NBER WORKING PAPER SERIES

\title{
THE ECONOMICS OF OPTIONS-IMPLIED INFLATION PROBABILITY DENSITY FUNCTIONS
}

\author{
Yuriy Kitsul \\ Jonathan $\mathrm{H}$. Wright \\ Working Paper 18195 \\ http://www.nber.org/papers/w18195
}

\author{
NATIONAL BUREAU OF ECONOMIC RESEARCH \\ 1050 Massachusetts Avenue \\ Cambridge, MA 02138 \\ June 2012
}

The views expressed in the paper are those of the authors and do not necessarily reflect views of the Federal Reserve Board, its staff, the Federal Reserve System or the National Bureau of Economic Research. The authors are responsible for any errors or omissions.

NBER working papers are circulated for discussion and comment purposes. They have not been peerreviewed or been subject to the review by the NBER Board of Directors that accompanies official NBER publications.

(C) 2012 by Yuriy Kitsul and Jonathan H. Wright. All rights reserved. Short sections of text, not to exceed two paragraphs, may be quoted without explicit permission provided that full credit, including (C) notice, is given to the source. 
The Economics of Options-Implied Inflation Probability Density Functions

Yuriy Kitsul and Jonathan H. Wright

NBER Working Paper No. 18195

June 2012

JEL No. C22,E31,E44,G12

\begin{abstract}
$\underline{\text { ABSTRACT }}$
Recently a market in options based on CPI inflation (inflation caps and floors) has emerged in the US. This paper uses quotes on these derivatives to construct probability densities for inflation. We study how these pdfs respond to news announcements, and find that the implied odds of deflation are sensitive to certain macroeconomic news releases. We compare the option-implied probability densities with those obtained by time series methods, and use this information to construct empirical pricing kernels. The options-implied densities assign considerably more mass to extreme inflation outcomes (either deflation or high inflation) than do their time series counterparts. This yields a U-shaped empirical pricing kernel, with investors having high marginal utility in states of the world characterized by either deflation or high inflation.
\end{abstract}

Yuriy Kitsul

Federal Reserve Board

20th and C Sts NW

Washington DC 20551

yuriy.kitsul@frb.gov

Jonathan H. Wright

Department of Economics

Johns Hopkins University

3400 N. Charles Street

Baltimore, MD 21218

and NBER

wrightj@jhu.edu 


\section{Introduction}

Fifteen years ago, the US Treasury began issuing index-linked debt. The spreads between the yields on these Treasury Inflation Protected Securities (TIPS) and the yields on their nominal counterparts - known as inflation compensation or breakevens - have become widely used as a real-time measure of investors' inflation expectations. They are commonly cited by Federal Reserve officials. A growing literature attempts to decompose these into inflation expectations, inflation risk premia and liquidity premia (see, Gürkaynak, Sack and Wright (2010), Pflueger and Viceira (2011), Campbell, Sunderam and Viceira (2010), Christensen, Lopez and Rudebusch (2010), D'Amico, Kim and Wei (2010), Grishchenko and Huang (2012) among others). Subsequently an over-the-counter market in inflation swaps emerged (Fleckenstein, Longstaff and Lustig (2010)). These are contracts where one party agrees to pay an interest rate on a notional underlying principle that is fixed at the start of the contract, while the other party agrees to pay the realized inflation rate on that same notional principle. Only the net of the two amounts actually changes hands. Under risk-neutrality, the fixed rate should equal expected inflation over the life of the contract.

Much more recently, a new market has emerged that is potentially considerably more powerful in providing direct market-based measures of investors' inflation beliefs. It is the market for inflation caps and floors - option-like securities whose payoff is tied to the realized inflation rate. The market developed first in the euro area and the UK, but has expanded in the US during the last few years. This is no doubt in part because of heightened investor concerns about the possibilities of deflation or of high 
inflation in the wake of the financial crisis. Unlike TIPS or inflation swaps, these new inflation derivatives provide direct information about the whole probability density for inflation, not just inflation expectations. This is naturally of great potential interest to a forward-looking central bank with an inflation objective.

In this paper, we use prices of inflation floors and caps to form implied probability density functions (pdfs) for inflation at different maturities, at the daily frequency over the last 2-1/2 years. While the sample period is short, it is of course a period of exceptional turbulence in the US economy and financial markets.

Our emphasis is on the economic interpretation of these inflation pdfs. In an event-study approach, we relate them to macroeconomic news announcements, finding that certain news announcements significantly impact the implied probabilities of deflation, and of high inflation. We construct a measure of FOMC announcement-day surprises and find that these do not have a significant effect on implied pdfs. However, the inflation pdfs did change over the time period that the market expectations about the second round of large scale asset purchases or LSAP-2 were formed in the fall of 2010.

These implied inflation pdfs are worked out under an assumption of risk-neutrality. We can however compare the pdfs to the density forecasts that would be formed by an econometrician. We find that our option-implied pdfs put substantially more weight on both high inflation and on deflation than their objective counterparts. That implies that the pricing kernel of investors is U-shaped in inflation, with investors having high marginal utility in both the state of the world where inflation is high and in the deflationary state. 
The plan for the remainder of this paper is as follows. Section 2 discusses the inflation floors and caps, and the extraction of the implied pdfs. Section 3 is an event-study analysis that relates these pdfs to certain news announcements. Section 4 compares the option-implied pdfs to econometric-based "physical" density forecasts, in order to obtain an empirical pricing kernel. Section 5 contains some robustness checks and extensions, while section 6 concludes.

\section{Inflation Caps and Floors}

Throughout this paper, we will work with zero-coupon inflation floors and caps; these are analytically by far the most convenient forms of these securities to work with. A zero-coupon inflation cap is a contract entered into at time $t$. The seller of the cap promises to pay a fraction $\max \left((1+\pi(n))^{n}-(1+k)^{n}, 0\right)$ of a notional underlying principle as a single payment in $n$ years' time, where $\pi(n)$ denotes the average annual CPI inflation rate ${ }^{\square}$ from $t$ to $t+n$, and $k$ denotes the strike of the cap. Without loss of generality, we normalize the notional underlying principle to $\$ 1$. In exchange for this, the buyer makes an up-front payment of $P_{t}(k, n)$. The buyer receives collateral to ensure that they will receive their payment at the end of the contract. Obviously, if inflation ends up being lower than $k$, then the option expires out-of-the money and ends up being worthless. A zero-coupon inflation floor is identical, except that the payment is $\max \left((1+k)^{n}-(1+\pi(n))^{n}, 0\right)$.

The market for inflation floors and caps is still in its infancy. The nominal Treasury market is far more liquid than the TIPS market, which is in turn more

\footnotetext{
${ }^{1}$ Headline CPI, not seasonally adjusted.
} 
liquid than the market for inflation swaps, and that is in turn more liquid than the market for inflation floors and caps. Still, according to a dealer, about $\$ 22$ billion of notional principle was traded in the inter-dealer market in 2011, which represents an increase of around $200 \%$ from 2010. Economists have a strong presumption that the prices that individuals are willing to pay reflect their beliefs, even when the stakes may not be that high. In experimental game theory, it is common to study individuals' behavior when tiny sums are at stake. Prediction markets are a good example of cases in which the stakes are small, but there is strong evidence that prices are nonetheless quite informative (Wolfers and Zitzewitz (2004)). The dollar trading volumes in inflation derivatives are minuscule relative to the Treasury market, but still big enough to presumably reflect the beliefs of traders in this market, and far bigger than those in experimental games and in prediction markets.

It is hard to know who are the participants in the market for inflation floors and caps. However, based on SEC filings, we can see that mutual funds and insurance companies participate in this market. They both buy and sell protection against both inflation and deflation. For example, PIMCO has written a substantial amount of inflation floors.

We obtained daily quotes on zero-coupon inflation caps at strike prices of 1,2 , $3,4,5$ and 6 percent, and on zero-coupon inflation floors at strike prices of $-2,-1$, 0,1,2 and 3 percent. The maturities are 1, 3, 5, 7 and 10 years. The data were kindly provided to us by BGC Partners. The sample period is from October 6, 2009

\footnotetext{
${ }^{2}$ Anecdotal reports suggest that the most actively traded floors and caps are currently those at 0 and 5 percent strikes, respectively.
} 
to March 27, 2012.

We use these quotes to form implied pdfs for inflation, but without assuming normality, as it is especially useful to have measures of investors' perceptions of tail outcomes. Our approach to forming the implied pdfs is a simple one based on the methodology of Breeden and Litzenberger (1979). Let us suppose that inflation over the next $n$ years can be approximated as having only integer support. If we consider a butterfly portfolio that involves buying caps with strikes of $k-1$ percent and $k+1$ percent while shorting two caps with a strike of $k$ percent, then this is a pure ArrowDebreu security with a payoff of $\$ 1$ if inflation is $k$ percent and zero otherwise, for any integer $k$. Let $p_{k, n}$ denote the probability that $\pi(n)=k$. A risk-neutral investor will pay $e^{-r_{n} n} p_{k, n}$ for this Arrow-Debreu security, where $r_{n}$ denotes the continuouslycompounded interest rate for $n$ years. As the final payment is secured by collateral, we wanted to use a risk-free rate for discounting, and so discount by the nominal Treasury term structure, using the dataset of Gürkaynak, Sack and Wright (2007).

This mechanically gives us the risk-neutral probabilities of inflation being $-2,-1$, $0, \ldots .5$ percent. As for the tails, if an investor buys an inflation cap at 5 percent and shorts one at 6 percent, then this investor receives $\$ 1$ if inflation is 6 percent or more and zero otherwise. This gives the probability of inflation being 6 percent or higher. The same works in the left tail as well, yielding the probability of inflation being -2 percent or lower. Thus we have essentially the whole term structure of inflation pdfs.

\footnotetext{
${ }^{3}$ There also exist year-over-year inflation floors and caps, securities in which the payment is based on the difference between the strike price and actual inflation in each year over the life of the contract. It is possible to use these to form implied inflation pdfs (Mercurio (2005), Mercurio
} 
Figures 1 and 2 show the resulting pdfs at all the available maturities on two sample days - June 10, 2010 and February 28, 2011, respectively. The implied pdf in June 2010 put substantial odds on deflation over the medium term, and was clearly skewed to the left. This is likely in part at least indicative of the concerns about further disinflation that prompted the Fed to introduce LSAP-2 (also sometimes referred to as QE2) later in that year. In contrast, in February 2011, the implied pdf was more symmetric, and indeed appeared to be approximately normal. The implied pdfs shown in Figures 1 and 2 both exhibit quite high variance. For example, the implied standard deviation of average inflation over the next ten years is about 1.5 percentage points in both figures. That seems high, though of course concerns about inflation becoming unanchored, in either direction, have been elevated over this period. It is important to remember that these implied pdfs are based on an assumption that agents are risk neutral. More about this in section 4.

As another way to report evolving perceptions of inflation risk that does not focus on two arbitrarily chosen days, we can plot the probability of deflation (defined here as inflation falling to 0 percent and below) against time (Figure 3) and the probability of high inflation (defined as inflation rising to 4 percent and above) against time (Figure 4). At the one-year horizon, the implied probability of deflation was high in 2010 and fell in 2011. The odds of deflation at longer horizons rose in late 2010 and again in late 2011, which were both times of considerable concern about the durability of the economic recovery in the wake of ongoing financial turmoil. The odds of high inflation rose at all horizons in late 2010 and early 2011, before dropping

and Moreni (2006), Kruse (2011)), but it is much harder. Meanwhile, our focus in this paper is not on the mechanics of extracting the risk-neutral inflation pdfs per se, but rather on their economic interpretation. 
off later in the sample.

\subsection{The Embedded Deflation Option in TIPS}

A different source of information about inflation risks is available from TIPS. TIPS bonds have the property that the principal repayment cannot be less than the face value of the bond, even if the price level falls over the life of the bond. This gives TIPS an option-like feature in which the "strike price" is the reference CPI (the price level at the time that the bond is issued). For a newly issued bond, any deflation will result in this option being in the money. For a bond issued, say, five years ago, however, the deflation has to have been very severe - enough to unwind all the cumulative inflation over the past five years - before this deflation option has any value. Thus comparing the real yields on pairs of TIPS with comparable maturity dates but different reference CPIs contains information about the odds of deflation (again under risk-neutrality). At times during recent years, these spreads such pairs of TIPS bonds traded at quite different yields, indicating substantial odds of deflation and/or a big deflation risk premium. Authors that have used the embedded-option in TIPS to measure the odds of deflation under risk neutrality include Wright (2009), Christensen, Lopez and Rudebusch (2011) and Grishchenko, Vanden and Zhang (2011). The TIPS market is more liquid than the market in inflation floors and caps. But the information on inflation risks that can be gleaned from comparing TIPS is far more limited; it only gives odds of deflation, not a complete pdf. And the comparison of TIPS yields could be affected by other factors, such as differences in liquidity across TIPS securities,

\footnotetext{
${ }^{4} \mathrm{~A}$ "movie" showing the pdf at the ten-year horizon day-by-day is available at http://www.econ. jhu.edu/People/Wright/inflationpdf.html.
} 
and the fact that no two TIPS have exactly the same maturity date (so that the comparison could be distorted by the seasonal pattern in CPI). Thus, in this paper, we use inflation floors and caps rather than comparison of TIPS yields as they are a much cleaner and more complete measure of investor perceptions of inflation risks.

\section{Events that Move the Inflation PDFs}

While asset prices ought to be related to economic fundamentals, the link between the two is often frustratingly difficult to uncover. But the high-frequency reaction of asset prices to macroeconomic news announcements can represent a rich source of information about the relationship between financial asset prices and our measures of economic fundamentals. In a small window around a major news announcement, the announcement swamps any other public or private information that becomes available, and so relating the surprise component of this announcement to the change in asset prices is akin to a "natural experiment". For example, it is notoriously hard to relate exchange rates to any fundamentals. Nonetheless, Andersen, Bollerslev, Diebold and Vega (2003) find that in short intradaily windows around macroeconomic news announcements, there is a systematic relationship between macroeconomic surprises and exchange rate changes.

Accordingly, we relate daily changes in our implied inflation pdfs to nine leading macroeconomic announcements. Table 1 lists the announcements, their frequency and release times. For all announcements other than the FOMC announcement, the surprise component of each announcement is measured as the real-time actual value less the median expectation from the survey conducted by Money Market Services 
(MMS) on the previous Friday. For the FOMC announcement, we are faced with the difficulty that this is the period at which the federal funds rate is stuck at the zero bound - any properly measured monetary policy surprises based on the federal funds would necessarily be identically equal to zero. But the FOMC announcements over this period contain information about the expected duration of the zero interest rate period and also about Fed asset purchases. As in Wright (2011), we quantify the surprise components of these announcements by the first principal component of the intraday change in the yields on two-, five-, ten- and thirty-year Treasury futures from 15 minutes before the time of the FOMC announcement to 1 hour and 45 minutes afterwards. It is hard to see how these jumps in yields owe to anything other than the FOMC announcements. The FOMC announcements that we consider include both FOMC meetings and important speeches by FOMC members relating to the outlook for monetary policy.

The event-study regressions that we run are of the form:

$$
\Delta p_{k, n, t}=\Sigma_{j=1}^{J} \beta_{j} s_{j t}+\varepsilon_{t}
$$

where $\Delta p_{k, n, t}$ is the risk-neutral probability of deflation, or of inflation exceeding 4 percent over the next $n$ years, as of day $t$, while $s_{j t}$ denotes the surprise component of an announcement of type $j$. The regression is run over all days where there is at least one news announcement: the surprise is set to zero for news types for which there is not an announcement on that day. The device of regressing yield changes on surprise components of all different types of announcements jointly accommodates

\footnotetext{
${ }^{5}$ These are normalized so that a drop in the level of interest rates around the FOMC corresponds to a positive surprise.
} 
the possibility of multiple announcements coming out concurrently.

The results are shown in Table 2 (for deflation) and Table 3 (for high inflation). The probabilities are in percentage points, the macroeconomic surprises are in the units listed in Table 1. For example, the effect of a CPI surprise on the deflation probability at the one-year horizon is reported as -10.94 . This means that if CPI were to come in a full percentage point above expectations (a very big surprise indeed), then the implied the probability of negative CPI inflation over the next 12 months would fall by 10.94 percentage points.

For all of the macroeconomic surprises that we consider, a positive surprise corresponds to higher-than-expected economic activity/inflation. It is not surprising that most estimates in Table 2 are negative; surprises indicating more strength in aggregate demand lower the perceived risk of deflation. At the one-year horizon, CPI is the only macroeconomic surprise that has a significant impact on deflation risk - of course CPI surprises should mechanically have an effect on deflation risk, since inflation caps and floors are based on the CPI. At longer horizons, higher than expected releases of existing home sales, nonfarm payrolls, PPI and retail sales all significantly lower the perceived odds of deflation. FOMC surprises do not have any statistically significant effect on deflation risk. One of the channels through which unconventional monetary policy was intended to support the economy was by lowering the risk of deflation. That effect does not show up in the approach considered here, in

\footnotetext{
${ }^{6}$ Strictly, an $h$-year inflation cap or floor refers to the $h$-year inflation rate starting about two months before the start date of the contract. This indexation lag is familiar to inflation-related assets and is necessitated by delays in compiling CPI data. But of course this means that a surprise in the CPI index for the last month enters directly into the cap/floor payoff and so should mechanically have a big effect on the pdf, especially at shorter horizons.
} 
which we link derivative-based inflation probabilities and FOMC-day surprises constructed from Treasury futures. It should be noted, however, that the expectations about unconventional monetary policy over our sample period were shaped not only by FOMC announcements but also by other factors such as speeches by the Federal Reserve officials and discussions in the media. ${ }^{\square}$ Indeed, inflation probability distributions became more skewed toward higher inflation outcomes during the period from late August to early November 2010, over which expectations for LSAP-2 were priced in by investors. On the day of the actual LSAP-2 announcement, Nov. 3 of 2010, deflation odds fell and probability of high inflation rose slightly.

Most of the estimates in Table 3 are positive; surprises indicating more strength in aggregate demand raise the perceived risk of inflation exceeding 4 percent. The effects of CPI surprises on the perceived probability of high inflation at the one- and three-year horizons are both statistically significant. But, apart from existing home sales, no other macroeconomic surprises have any significant effect on the odds of high inflation at horizons below ten years.

Overall, there is a bit more evidence of deflation probabilities being sensitive to macroeconomic news than for high inflation probabilities being sensitive to news, at least at medium horizons (three to seven years). Perhaps this is a result that is particular to the sample period. News about demand may have had a heightened impact on investors' perceptions of the odds of the economy becoming stuck in a deflationary spiral, which would not be the case at a time when the economy was far

\footnotetext{
${ }^{7}$ See, for example, a Bloomberg article of October 28, 2010, by Rebecca Christie and Craig Torres for a snapshot of market expectations regarding additional monetary stimulus shortly before the FOMC meeting of November 2010, at which the LSAP-2 was announced.
} 
from the zero lower bound.

Table 4 lists the days of the ten biggest absolute changes in the options-implied odds of deflation or high inflation at the ten-year horizon. For these days, we went back and searched Wrightson ICAP daily summaries of financial markets for news stories that could help explain the change. The possible contributory factors that we found are also listed in Table 4. There are some cases in which changes in optionimplied odds are consistent with news stories. For example, the fluctuations in the odds of deflation in October 2010 can be at least partially explained by shifting speculation about the size of the LSAP-2 program that the FOMC was expected to announce at its meeting on November 3 of that year. At the same time, most substantial changes in the inflation pdfs occurred on days when it is hard to find news or an event that provides even a partial plausible explanation. It is however a long-standing puzzle that news announcements can explain only a small share of asset price variation, and indeed that the biggest asset price movements occur in the absence of any apparent public information (Fair (2002)).

One might wonder if the announcement by the FOMC of a 2 percent long-run goal for inflation on January 25, 2012 affected these probability densities. They were little changed on the day of the announcement, and indeed over several subsequent days.

\section{Inflation Risk Premia}

The implied pdfs that we have obtained are based on the assumption of risk-neutrality. In standard finance terminology, they are obtained under the Q measure. Agents are 
presumably not risk neutral, and so the probabilities will differ from a physical density forecast (the $\mathrm{P}$ measure). As is well known, the risk-neutral probability of a particular state of the world is equal to the physical probability times the pricing kernel, in that state of the world. Outcomes in which the marginal utility of an investor is high will be overweighted under the $\mathrm{Q}$ measure. The ratio of the estimated pdf under the $\mathrm{Q}$ measure to that under the $\mathrm{P}$ measure represents the empirical pricing kernel (Rosenberg and Engle (2002)).

We consider four different time series approaches to form a physical density forecast for inflation. These are:

1. The unobserved component stochastic volatility model (UCSV), which Stock and Watson (2007) find to provide good forecasts for inflation. The model is univariate. Inflation is $\pi_{t}$, which can be decomposed as:

$$
\pi_{t}=\tau_{t}+\sigma_{T, t} \eta_{t}^{T}
$$

and

$$
\tau_{t}=\tau_{t-1}+\sigma_{P, t} \eta_{t}^{P}
$$

where $\left(\eta_{t}^{T}, \eta_{t}^{P}\right)^{\prime}$ is $\operatorname{iidN}\left(0, I_{2}\right), \log \left(\sigma_{T, t+1}^{2}\right)=\log \left(\sigma_{T, t}^{2}\right)+\psi_{1, t}, \log \left(\sigma_{P, t+1}^{2}\right)=\log \left(\sigma_{P, t}^{2}\right)+$ $\psi_{2, t}$ and $\left(\psi_{1, t}, \psi_{2, t}\right)^{\prime}$ is $\operatorname{iidN}\left(0, \gamma I_{2}\right)$, with $\left(\eta_{t}^{T}, \eta_{t}^{P}\right)^{\prime}$ and $\left(\psi_{1, t}, \psi_{2, t}\right)^{\prime}$ being mutually independent. The model can be fitted by Markov Chain Monte Carlo methods, and can be used to simulate a density forecast for inflation. Following Stock and Watson (2007), the parameter $\gamma$ is fixed at 0.2 .

2. The unobserved component stochastic volatility as in (1), except that the correlation between $\eta_{t}^{T}$ and $\psi_{1, t}$ is $\rho_{1}$ and the correlation between $\eta_{t}^{P}$ and $\psi_{2, t}$ is $\rho_{2}$. This 
introduces a leverage effect. We refer to this as the UCSV model with correlated errors (UCSV-CE), and use the algorithm of Omori et al. (2007) to obtain the posterior distribution of the parameters, which we then use to simulate a density forecast.

3. An AR(4) model for inflation, with an EGARCH specification for the errors. The UCSV model allows the density forecasts to be fat-tailed, but restricts them to be symmetric. The AR-EGARCH specification loosens this restriction.

4. The VAR model with time-varying parameters and stochastic volatility, proposed by Primiceri (2005). The VAR uses real-time data on quarterly CPI inflation, the federal funds rate and the unemployment rate. Following Primiceri, the specification has two lags and coefficients that follow random walks, while the error terms exhibit stochastic volatility. The VAR is constrained to be stationary in every period. We evaluate the posterior distribution of the parameters, and then use this to simulate a density forecast for inflation.

In Figure 1, we reported the options-implied pdfs for inflation, as of June 10, 2010. Figures 5-8 plot the corresponding physical pdfs for inflation based on the UCSV, UCSV-CE, AR-EGARCH and TVP-VAR models, respectively, using the CPI data that were available as of that date. ${ }^{\mathbf{n}}$ Figures 9-12 plot the ratio of the options-implied to these physical pdfs, which represent estimates of the empirical pricing kernel.

The physical pdfs in Figure 5-8 assign low odds to tail outcomes, especially for

\footnotetext{
${ }^{8}$ Note that our forecast density takes account of parameter uncertainty - we use draws of the parameters from their posterior distribution. The priors for $\rho_{1}$ and $\rho_{2}$ are independent and uniform on $[-1,1]$.

${ }^{9}$ These use CPI inflation data from the start of 1960 up to April 2010, the last available data on June 10, 2010.
} 
the AR-EGARCH specification (Figure 6). Note that this is a stationary specification. The density forecast for average inflation over the horizon $h$ that is implied by the AR-EGARCH model converges by construction to a degenerate distribution equal to the sample average of inflation in the limit as $h$ goes to infinity. This is not true for any of the other models, which all allow for a slowly varying local mean of inflation. The UCSV and TVP-VAR models both imply symmetric density forecasts, by construction. That is not true for the UCSV-CE and AR-EGARCH models, although their density forecasts show little sign of skewness.

For any of the four physical pdfs in Figures 5-8, the tail outcomes have lower odds under the $\mathrm{P}$ measure than under the $\mathrm{Q}$ measure. The direct implication of this is that the empirical pricing kernel is very high for both severe deflation outcomes and for high inflation outcomes (Figures 9-12). The empirical pricing kernel is thus generally U-shaped, although the relative marginal utilities in the deflationary and inflationary tails depends on the method that is used to form the forecast under the $\mathrm{P}$ measure.

These empirical pricing kernel results apply, of course, only to one day. To investigate the question over the rest of the sample period, we show the optionsimplied and physical probabilities of deflation over the whole sample (Figure 13) and, likewise, the options-implied and physical probabilities of inflation exceeding 4 percent (Figure 14). The physical probabilities are obtained in both cases from the UCSV model. The options-implied probabilities of deflation are consistently above the physical probabilities. It's perhaps a little less stark for the odds of high inflation. However, the options-implied probabilities of high inflation are nearly always above 
the physical probabilities, at horizons beyond one year. So the U-shaped pricing kernel does not apply to one day alone.

The U-shaped pricing kernel in turn has implications for the risk premia in nominal bonds. We have found direct and model-free evidence that investors view both high inflation and deflation as states of the world in which their marginal utility is high. Consequently, assets that pay off in these scenarios are valuable hedges. Nominal bonds are assets whose real value is eroded by high inflation, but which do well in a deflationary environment. Until recently, deflation seemed a very remote possibility, and so over the range of plausible inflation outcomes, investors would have seen marginal utility as upward sloping, leading nominal bonds to command a positive risk premium. But in the wake of the financial crisis, there are substantial odds of both high inflation and deflation, and that should make the risk premium on nominal bonds be lower, or even negative. Using a quite different approach Campbell, Sunderam and Viceira (2010) argue that nominal bonds have recently switched from being exposed to inflation risk (with positive term premia) to being deflation hedges (with negative term premia), which is entirely consistent with what we find in this paper. A simple approach to estimating term premia is to take the difference between long-term Treasury yields and average expected short-term interest rates measured by the Blue Chip Financial Forecasts survey. Term premia on ten-year Treasuries, estimated in this way, are shown in Figure 15. They trended down from over 2 percent in the late 1980s, to being slightly negative at the end of $2011 .{ }^{\mathbb{m}}$ Given the U-shaped

\footnotetext{
${ }^{10}$ Affine term structure models (such as that of Kim and Wright (2005)) show term premia declining over the 1990s and 2000s. This trend has continued into the financial crisis, and the term premium estimates of Kim and Wright are now mildly negative.
} 
pricing kernel, this would be consistent with investors shifting from being worried about high inflation alone to being worried about both high inflation and deflation.

\section{Robustness Checks and Extensions}

We also investigated alternative methods for reverse-engineering probability density functions from the prices of inflation floors and caps. One was to fit a mixture of two normals, picking the parameters so as to minimize the sum of squared percentage pricing errors. The other was to use the nonparametric procedure of Shimko (1993). Both of these gave similar probability density functions to those that we obtained in section 3 .

It would also be of interest to have a probability density for inflation over some period in the future. Alas, the inflation floors and caps are all contracts that are written on average inflation from the outset of the contract to the maturity date. Assuming risk neutrality, we can back out the marginal densities of average inflation over these horizons, but cannot extract the density for forward inflation without making further assumptions. For example, with five- and ten-year floors and caps, we can back out the marginal densities of inflation at five- and ten-year horizons, but working out the probability density function for inflation from five to ten years' hence is a deconvolution problem that can only be solved if we make some assumption about the dynamics of the inflation process, such as assuming that inflation in the first five and subsequent five years are mutually independent.

In Figure 16, we show the probability density functions for inflation from five to ten years' hence on four recent dates from December 2011 to April 2012, constructed 
assuming that inflation over the first five and subsequent five years are mutually independent. These dates were chosen because they are the dates that the New York Fed conducted surveys of primary dealers asking respondents for their judgmental density forecasts for inflation from five to ten years' hence. $\square$ The survey density is also included in Figure 16. Over this period, the survey density is virtually unchanged from one date to the next, and the options-implied densities are very stable too. Clearly, the options-implied densities assign much higher probabilities to both tails than do the survey respondents. We interpret this as further evidence for the Ushaped empirical pricing kernel.

\section{Conclusions}

In this paper, we have used quotes on inflation caps and floors to construct riskneutral probability densities for inflation over the last $2-1 / 2$ years. These pdfs do not require an assumption of normality, and indeed on some occasions the pdfs were skewed towards deflation. We have studied how these pdfs responded to certain announcements. While most of the variation in inflation pdfs cannot be tied to macroeconomic news announcements, the implied probability of deflation (and, to a lesser extent, the implied probability of high inflation) are both significantly related to the surprise components of certain macroeconomic news announcements. The pdfs that we have obtained are formed under an assumption of risk neutrality. Comparing

\footnotetext{
${ }^{11}$ Respondents are asked to assign probabilities to average inflation being less than 1 percent, 1-1.5, 1.5-2, 2-2.5, 2.5-3 or over 3 percent. The probabilities are then averaged over the 21 respondents. Aggregate survey results used in this study are publicly available at http : //www.newyorkfed.org/markets/primarydealer_survey_questions.html.
} 
them to econometric density forecasts allows us to see how investors marginal utility relates to inflation. We find that states of the world in which inflation is either very low or very high are ones in which investors have high marginal utility.

\section{References}

[1] Andersen, Torben G., Tim Bollerslev, Francis X. Diebold and Clara Vega (2003): Micro Effects of Macro Announcements: Real-Time Price Discovery in Foreign Exchange, American Economic Review, 93, pp.38-62.

[2] Breeden, Douglas T. and Robert H. Litzenberger (1978): Prices of State Contingent Claims Implicit in Options Prices, Journal of Business, 51, pp.621-651.

[3] Campbell, John Y., Adi Sunderam, and Luis M. Viceira (2010): Inflation Bets or Deflation Hedges? The Changing Risks of Nominal Bonds, working paper, Harvard University.

[4] Christensen, Jens H.E., Jose A. Lopez and Glenn D. Rudebusch (2010): Inflation Expectations and Risk Premiums in an Arbitrage-Free Model of Nominal and Real Bond Yields, Journal of Money, Credit and Banking, 42, pp.143-178.

[5] Christensen, Jens H.E., Jose A. Lopez and Glenn D. Rudebusch (2011): Pricing Deflation Risk with U.S. Treasury Yields, working paper.

[6] Christie, Rebecca and Craig Torres (2010): Fed Asks Dealers to Estimate Size, Impact of Debt Purchases, Bloomberg, available at http://www.bloomberg.com/news/2010-10-28/fed-asks-dealers-to-estimatesize-impact-of-debt-purchases.html, [accessed on April 25, 2012].

[7] D'Amico, Stefania, Don H. Kim, and Min Wei (2010): Tips from TIPS: the Informational content of Treasury Inflation-Protected Security prices, Finance and Economics Discussion Series, 2010-19.

[8] Fair, Ray C. (2002): Events that Shook the Market, Journal of Business, 75, pp.713-732.

[9] Fleckenstein, Matthias, Francis A. Longstaff, and Hanno Lustig (2010): Why does the Treasury Issue TIPS? The TIPS-Treasury Bond Puzzle, NBER working paper 16358 . 
[10] Grishchenko, Olesya V., Joel M. Vanden, and Jianing Zhang (2011): The Information Content of the Embedded Deflation Option in TIPS, Finance and Economics Discussion Series, 2011-58.

[11] Grishchenko, Olesya V. and Jing-Zhi Huang (2012): Inflation Risk Premium: Evidence from the TIPS Market, working paper.

[12] Gürkaynak, Refet S., Brian Sack, and Jonathan H. Wright (2007): The U.S. Treasury yield curve: 1961 to the present, Journal of Monetary Economics, 54, pp.2291-2304.

[13] Gürkaynak, Refet S., Brian Sack, and Jonathan H. Wright (2010): The TIPS Yield Curve and Inflation Compensation, American Economic Journal: Macroeconomics, 2, pp.70-92.

[14] Kim, Don H. and Jonathan H. Wright (2005): An Arbitrage-Free ThreeFactor Term Structure Model and the Recent Behavior of Long-Term Yields and Distant-Horizon Forward Rates, Finance and Economics Discussion Series, 2005-33.

[15] Kruse, Susanne (2011): On the Pricing of Inflation-Indexed Options, European Actuarial Journal, 1, pp.S379-S393.

[16] Mercurio, Fabio (2005): Pricing inflation-indexed derivatives, Quantitative Finance, 5, pp.289-302.

[17] Mercurio, Fabio and Nicola Moreni (2006): Inflation-Indexed SecuritiesInflation with a Smile, Risk, 19, pp.70-75.

[18] Omori Yasuhiro, Siddhartha Chib, Neil Shephard and Jouchi Nakajima (2007): Stochastic volatility with leverage: Fast likelihood inference, Journal of Econometrics, 140,pp.425-449.

[19] Pflueger, Carolin E. and Luis M. Viceira (2011): Inflation-Indexed Bonds and the Expectations Hypothesis, Annual Review of Financial Economics, 3, pp.139-158.

[20] Primiceri, Giorgio E. (2005): Time Varying Structural Vector Autoregressions and Monetary Policy, Review of Economic Studies, 72, pp.821-852.

[21] Rosenberg, Joshua V., and Robert F. Engle (2002): Empirical Pricing Kernels, Journal of Financial Economics, 64, pp.341-372.

[22] Shimko, David (1993): The Bounds of Probability, Risk, 6, pp. 33-37. 
[23] Stock, James H. and Mark W. Watson (2007): Why Has U.S. Inflation Become Harder to Forecast?, Journal of Money, Credit, and Banking, 39, pp.3-34.

[24] Wolfers, Justin and Eric Zitzewitz (2004): Prediction Markets, Journal of Economic Perspectives, 18, pp.107-126.

[25] Wright, Jonathan H. (2009): Comment on: "Understanding Inflation-Indexed Bond Markets" (by Campbell, Shiller, and Viceira), Brookings Papers on Economic Activity, Spring, pp.126-135.

[26] Wright, Jonathan H. (2011): What Does Monetary Policy do at the Zero Lower Bound?, NBER working paper 17154. 
Table 1: US Macroeconomic Announcements

\begin{tabular}{llll}
\hline \hline Data Release & Source & Frequency & Units \\
\hline CPI (Core) & BLS & Monthly & Percent change mom \\
Existing Home Sales & NAR & Monthly & Thousands \\
FOMC & Fed & 8 per Year & Basis Points \\
GDP (Advance) & BEA & Quarterly & Percent change qoq, ar \\
Housing Starts & Census & Monthly & Thousands \\
New Home Sales & Census & Monthly & Hundred Thousands \\
Nonfarm Payrolls & BLS & Monthly & Thousands \\
PPI (Core) & BLS & Monthly & Percent change mom \\
Retail Sales & Census & Monthly & Percent change mom \\
\hline \hline
\end{tabular}

Notes: Acronyms for the sources are as follows: BEA (Bureau of Economic Analysis), BLS (Bureau of Labor Statistics), Census (Bureau of the Census), Fed (Federal Reserve Board of Governors), NAR (National Association of Realtors). Acronyms for the units are: mom (month-over-month), qoq (quarter-over-quarter), ar (annualized rate). 
Table 2: Regression of Implied Probability of Deflation onto Macroeconomic Surprises

\begin{tabular}{lccccc}
\hline \hline & One Year & Three Years & Five Years & Seven Years & Ten Years \\
\hline CPI & $-10.94^{* * *}$ & -0.80 & -0.63 & -0.50 & -0.49 \\
Existing Home Sales & $(3.35)$ & $(2.83)$ & $(0.84)$ & $(0.74)$ & $(0.66)$ \\
& -3.65 & -0.43 & $-0.70^{* * *}$ & $-0.45^{* * *}$ & $-0.33^{* *}$ \\
FOMC & $(3.83)$ & $(0.32)$ & $(0.25)$ & $(0.17)$ & $(0.15)$ \\
& 1.13 & -0.06 & -0.16 & -0.08 & -0.13 \\
GDP (Advance) & $(0.80)$ & $(0.19)$ & $(0.19)$ & $(0.13)$ & $(0.17)$ \\
\multirow{4}{*}{ Housing Starts } & -0.48 & -0.11 & -0.04 & 0.06 & 0.05 \\
\multirow{2}{*}{ New Home Sales } & $(1.09)$ & $(0.44)$ & $(0.31)$ & $(0.26)$ & $(0.25)$ \\
& 1.41 & 2.36 & -0.36 & 1.97 & 1.87 \\
Nonfarm Payrolls & $(5.46)$ & $(1.72)$ & $(1.38)$ & $(1.75)$ & $(1.77)$ \\
& -15.87 & -9.16 & -1.59 & -0.27 & 0.23 \\
PPI & $(18.35)$ & $(6.93)$ & $(1.71)$ & $(1.27)$ & $(1.50)$ \\
& -0.43 & -0.20 & $-0.39^{*}$ & $-0.22^{*}$ & $-0.22^{* *}$ \\
Retail Sales & $(0.53)$ & $(0.17)$ & $(0.21)$ & $(0.12)$ & $(0.10)$ \\
& -0.71 & $-0.84^{*}$ & $-0.56^{* * *}$ & $-0.49^{* * *}$ & -0.16 \\
& $(1.05)$ & $(0.50)$ & $(0.19)$ & $(0.17)$ & $(0.14)$ \\
\hline \hline
\end{tabular}

Notes: This table reports estimates of the regressions of daily changes in the options-implied probability of average CPI inflation being negative over different horizons onto macroeconomic surprises. The probabilties are in percentage points; the units of the macroeconomic surprises are given in Table 1. Heteroskedasticity-robust standard errors are in parentheses. One, two and three asterisks denote statistical significance at the 10,5 and 1 percent levels, respectively. 
Table 3: Regression of Implied Probability of High Inflation onto Macroeconomic Surprises

\begin{tabular}{lccccc}
\hline \hline & One Year & Three Years & Five Years & Seven Years & Ten Years \\
\hline CPI & $6.91^{* * *}$ & $3.50^{* * *}$ & -1.42 & -2.45 & 2.21 \\
& $(1.74)$ & $(1.06)$ & $(3.71)$ & $(3.94)$ & $(2.85)$ \\
Existing Home Sales & 1.01 & 0.29 & $0.80^{*}$ & $0.71^{* *}$ & 0.68 \\
& $(1.06)$ & $(0.32)$ & $(0.47)$ & $(0.34)$ & $(0.43)$ \\
FOMC & -0.34 & 0.15 & -0.03 & 0.13 & 0.34 \\
GDP (Advance) & $(0.28)$ & $(0.16)$ & $(0.37)$ & $(0.26)$ & $(0.36)$ \\
\multirow{4}{*}{ Housing Starts } & 0.31 & 0.01 & -0.02 & 0.09 & 0.16 \\
& $(0.65)$ & $(0.29)$ & $(0.41)$ & $(0.38)$ & $(0.51)$ \\
New Home Sales & -1.08 & -0.36 & 0.42 & -1.95 & -2.87 \\
\multirow{2}{*}{ Nonfarm Payrolls } & $(1.66)$ & $(1.31)$ & $(1.96)$ & $(2.17)$ & $(4.12)$ \\
& -1.49 & -1.72 & 1.51 & 2.67 & $6.40^{* *}$ \\
PPI & $(1.93)$ & $(4.37)$ & $(2.57)$ & $(2.45)$ & $(2.92)$ \\
& 0.02 & 0.15 & 0.15 & 0.23 & $0.67^{* *}$ \\
Retail Sales & $(0.28)$ & $(0.17)$ & $(0.09)$ & $(0.16)$ & $(0.27)$ \\
& 0.18 & 0.15 & 0.00 & 0.52 & 0.52 \\
& $(0.51)$ & $(0.38)$ & $(0.16)$ & $(0.33)$ & $(0.56)$ \\
\hline \hline
\end{tabular}

Notes: This table reports estimates of the regressions of daily changes in the options-implied probability of average CPI inflation exceeding 4 percent per annum over different horizons onto macroeconomic surprises. The probabilties are in percentage points; the units of the macroeconomic surprises are given in Table 1. Heteroskedasticity-robust standard errors are in parentheses. One, two and three asterisks denote statistical significance at the 10,5 and 1 percent levels, respectively. 
Table 4: Days of Biggest Changes in Options-Implied Odds of Deflation or High Inflation

\begin{tabular}{lll}
\hline \hline Date & Change & Possible Contributory Factors \\
\hline $10 / 27 / 2010$ & +6.3 & WSJ story about size of QE2 \\
$10 / 8 / 2009$ & -5.1 & Lower-than-expected jobless claims \\
$11 / 1 / 2010$ & +4.7 & \\
$10 / 29 / 2010$ & -3.6 & Poll Indicating High Expectations for QE2 \\
$1 / 11 / 2010$ & +3.2 & \\
$3 / 3 / 2010$ & -2.4 & Better-than-expected ADP report \\
$1 / 9 / 2012$ & -1.5 & \\
$9 / 22 / 2011$ & +1.5 & Euro-area concerns \\
$10 / 27 / 2011$ & -1.5 & Deal to Stabilize Euro-area \\
$1 / 12 / 2010$ & -1.4 & \\
& & High Inflation \\
$2 / 7 / 2012$ & +10.6 & Agreement on Greek bailout \\
$9 / 15 / 2011$ & +7.0 & \\
$11 / 1 / 2010$ & +6.8 & \\
$10 / 27 / 2010$ & +5.7 & WSJ story about size of QE2 \\
$10 / 29 / 2010$ & +5.3 & Poll Indicating High Expectations for QE2 \\
$9 / 6 / 2011$ & -5.0 & Euro-area concerns \\
$12 / 16 / 2011$ & -4.9 & \\
$2 / 3 / 2012$ & -4.7 & \\
$9 / 22 / 2011$ & -4.6 & \\
$11 / 25 / 2011$ & +4.3 & \\
\hline \hline
\end{tabular}

Notes: This table reports the dates of the ten biggest absolute daily changes in the options-implied probability of average CPI inflation being negative (top panel) or exceeding four percent (bottom panel). The changes in the options-implied probabilities on these dates are shown in the second column, in percentage points. The third column lists possible contributory factors that we identified from Wrightson ICAP daily summaries of financial markets. 
Figure 1: Inflation PDFs June 10, 2010
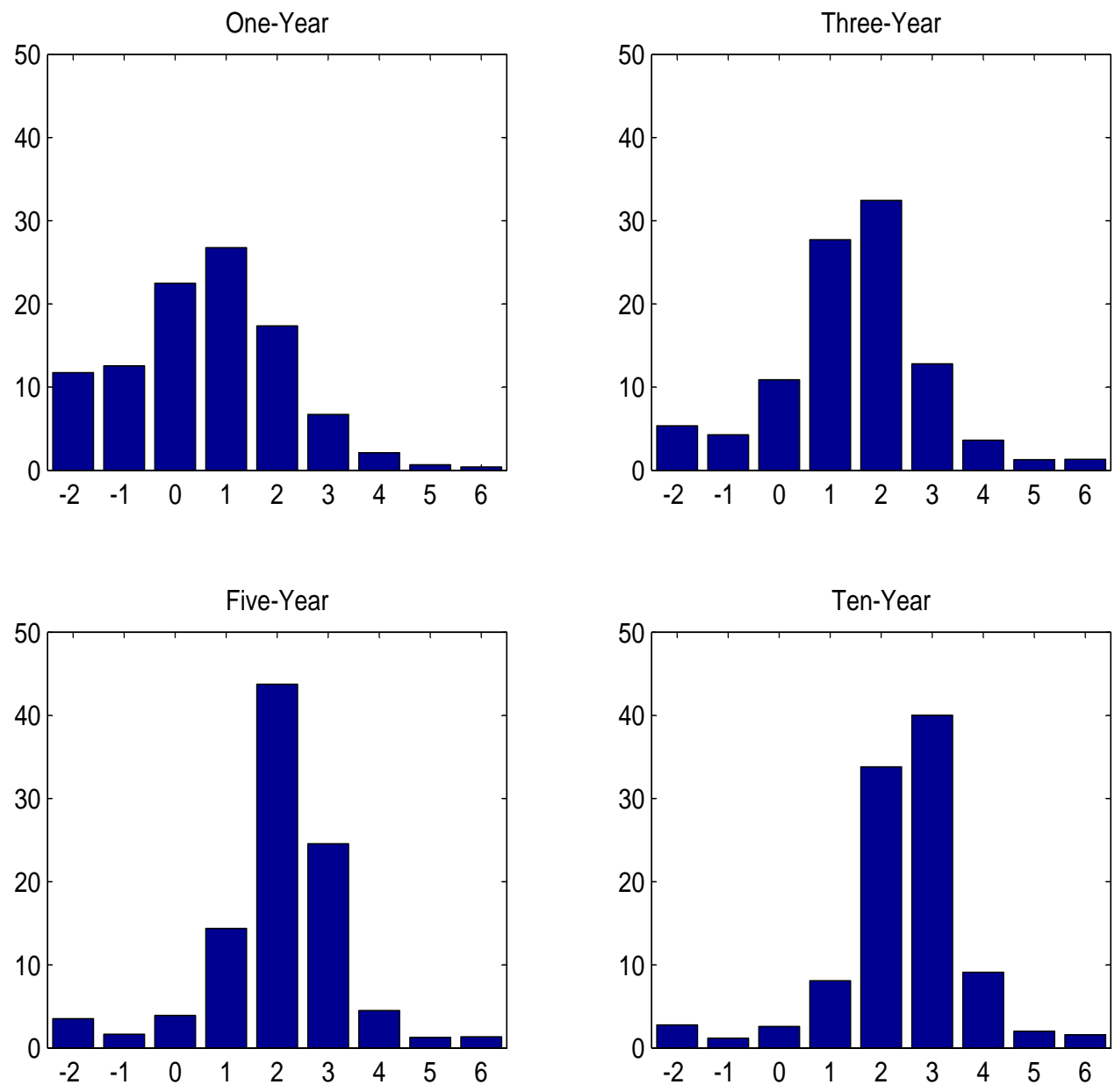

Notes: These are the pdfs for average CPI inflation over the next one, three, five and ten years constructed using inflation caps and floors, under an assumption of risk-neutrality. 
Figure 2: Inflation PDFs February 28, 2011
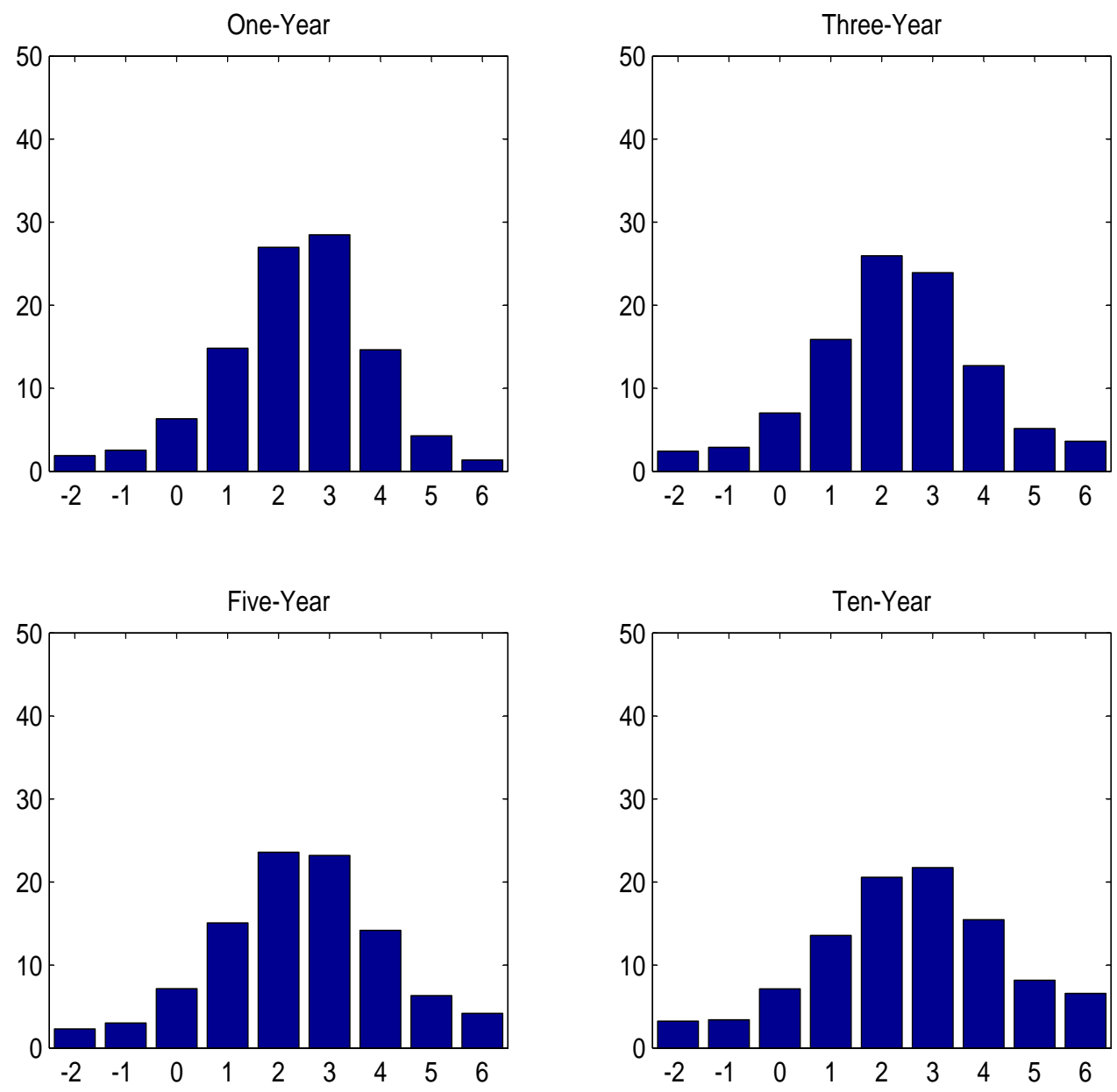

Notes: These are the pdfs for average CPI inflation over the next one, three, five and ten years constructed using inflation caps and floors, under an assumption of risk-neutrality. 
Figure 3: Probability of Deflation
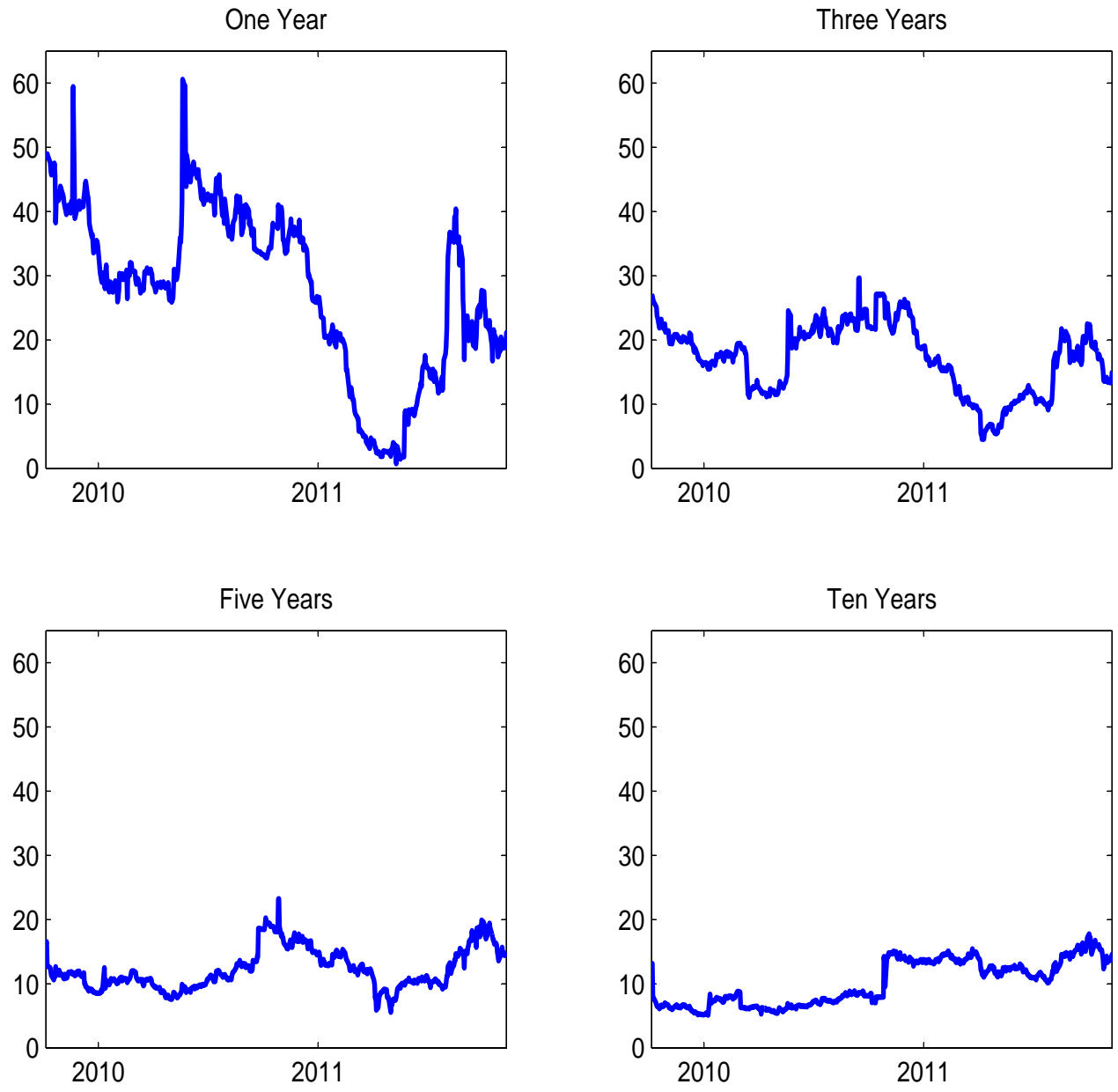

Notes: This shows the time series of probabilities of average CPI inflation over selected horizons being negative. These are constructed using inflation caps and floors, under an assumption of risk-neutrality. 
Figure 4: Probability of High Inflation
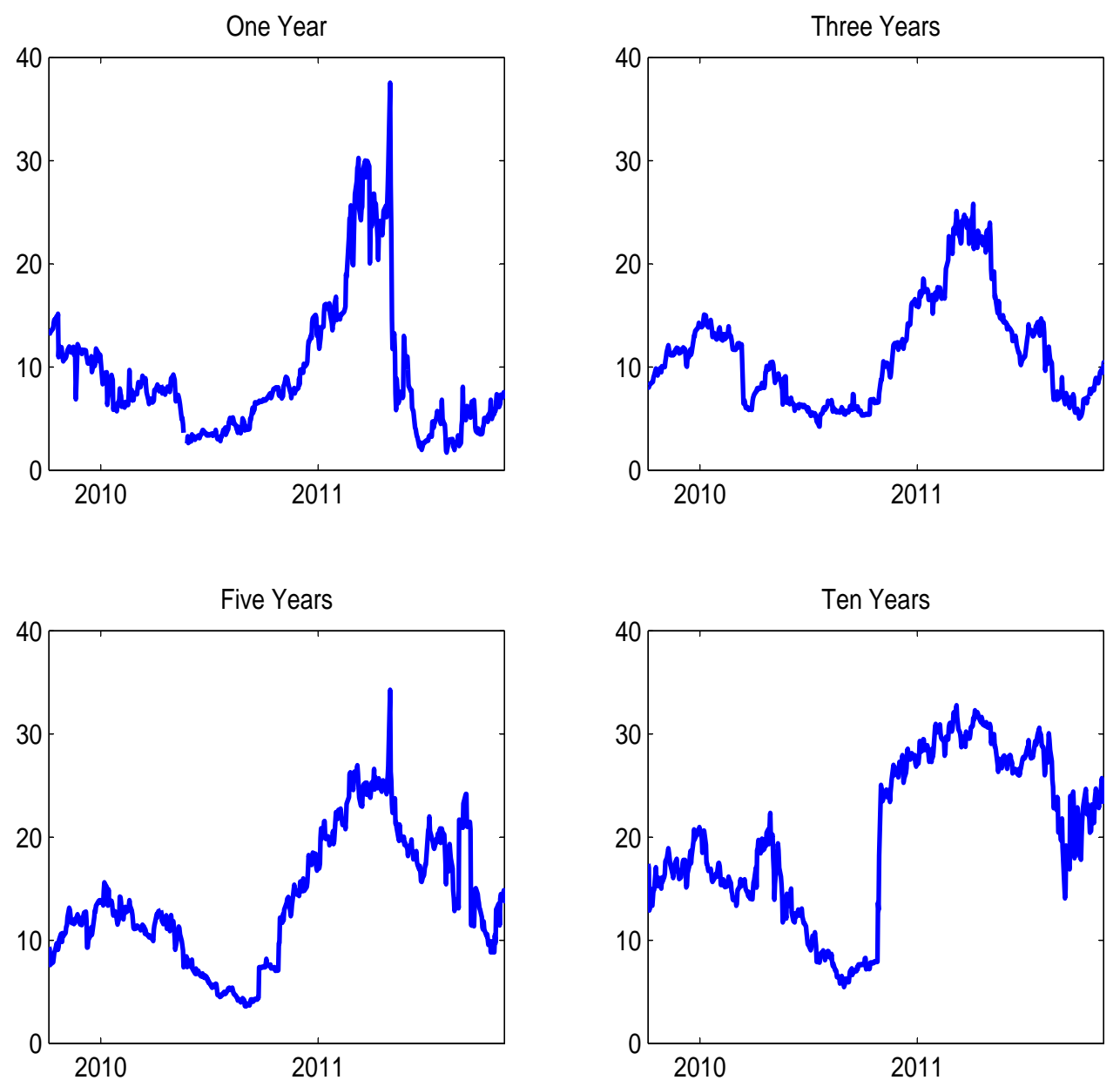

Notes: This shows the time series of probabilities of average CPI inflation over selected horizons exceeding 4 percent per annum. These are constructed using inflation caps and floors, under an assumption of riskneutrality. 
Figure 5: PDF for Inflation Based on UCSV Model
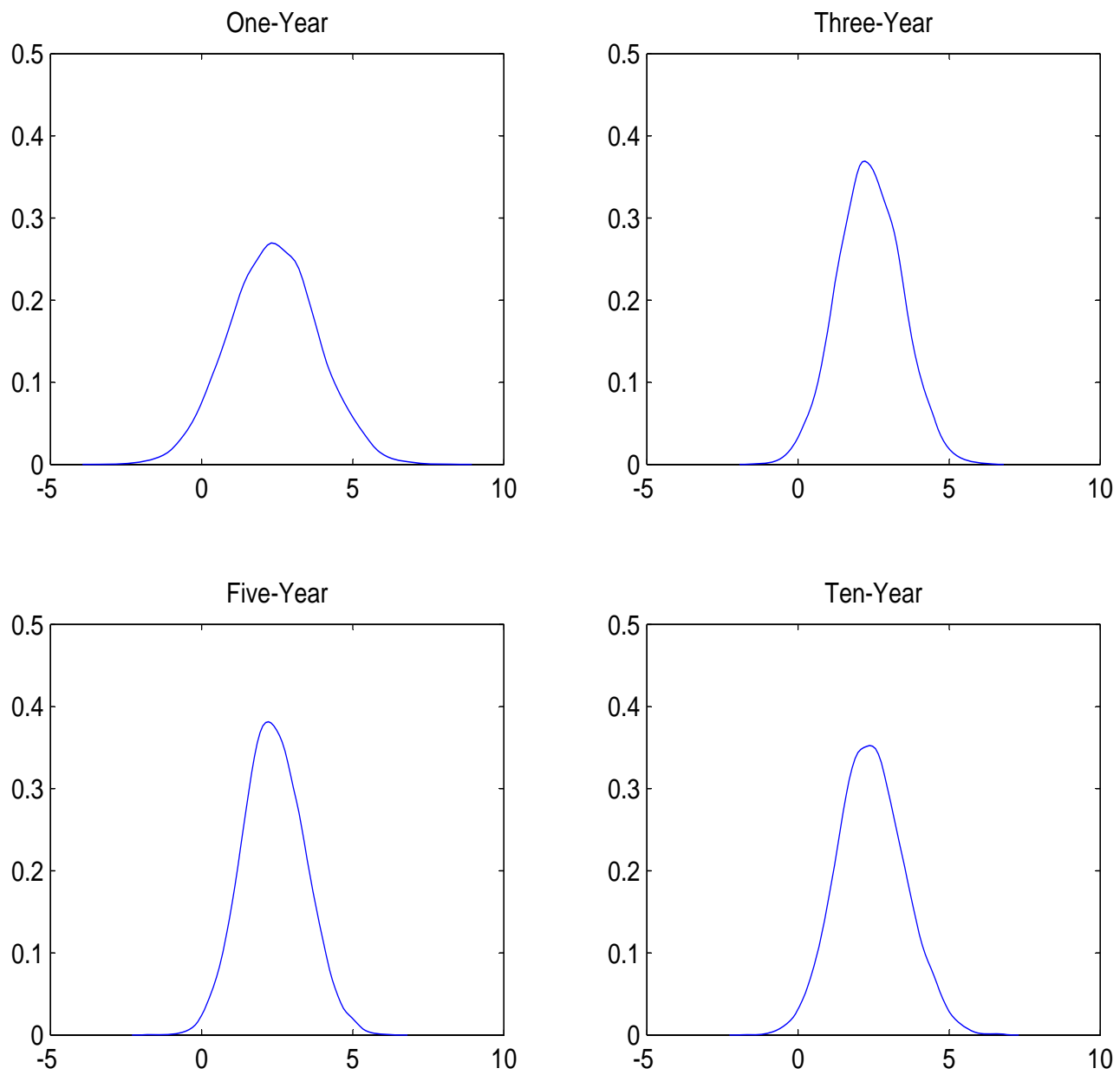

Notes: This shows the pdf for average CPI inflation over selected horizons based on the unobserved components stochastic volatility (UCSV) model of Stock and Watson (2007). The model was fitted to CPI data available as of June 10, 2010, and starting in 1960. 


\section{Figure 6: PDF for Inflation Based on UCSV Model with Correlated Errors}
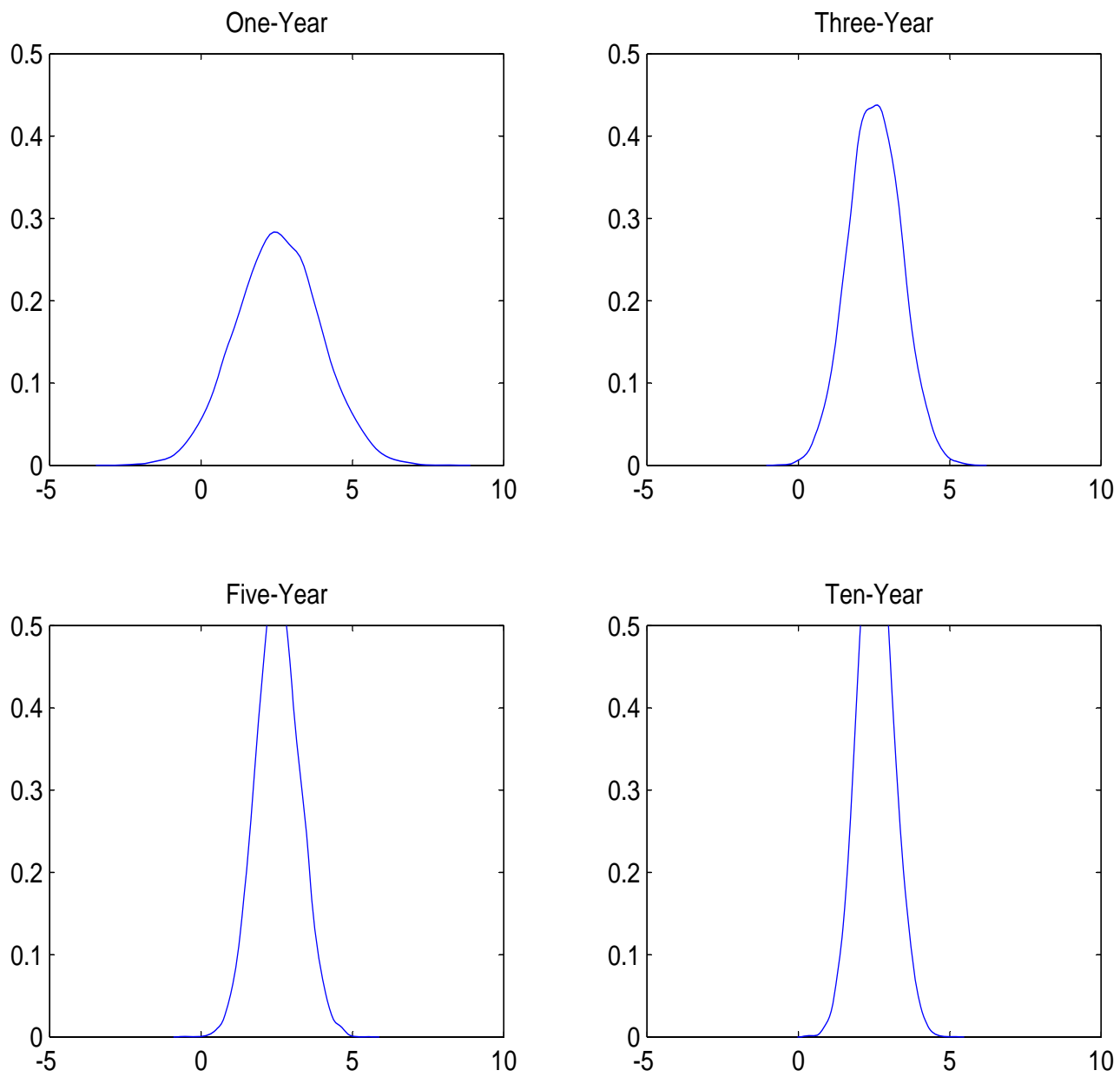

Notes: This shows the pdf for average CPI inflation over selected horizons based on the unobserved components stochastic volatility (UCSV) model of Stock and Watson (2007). The model was fitted to CPI data available as of June 10, 2010, and starting in 1960. 


\section{Figure 7: PDF for Inflation Based on AR-EGARCH Model}
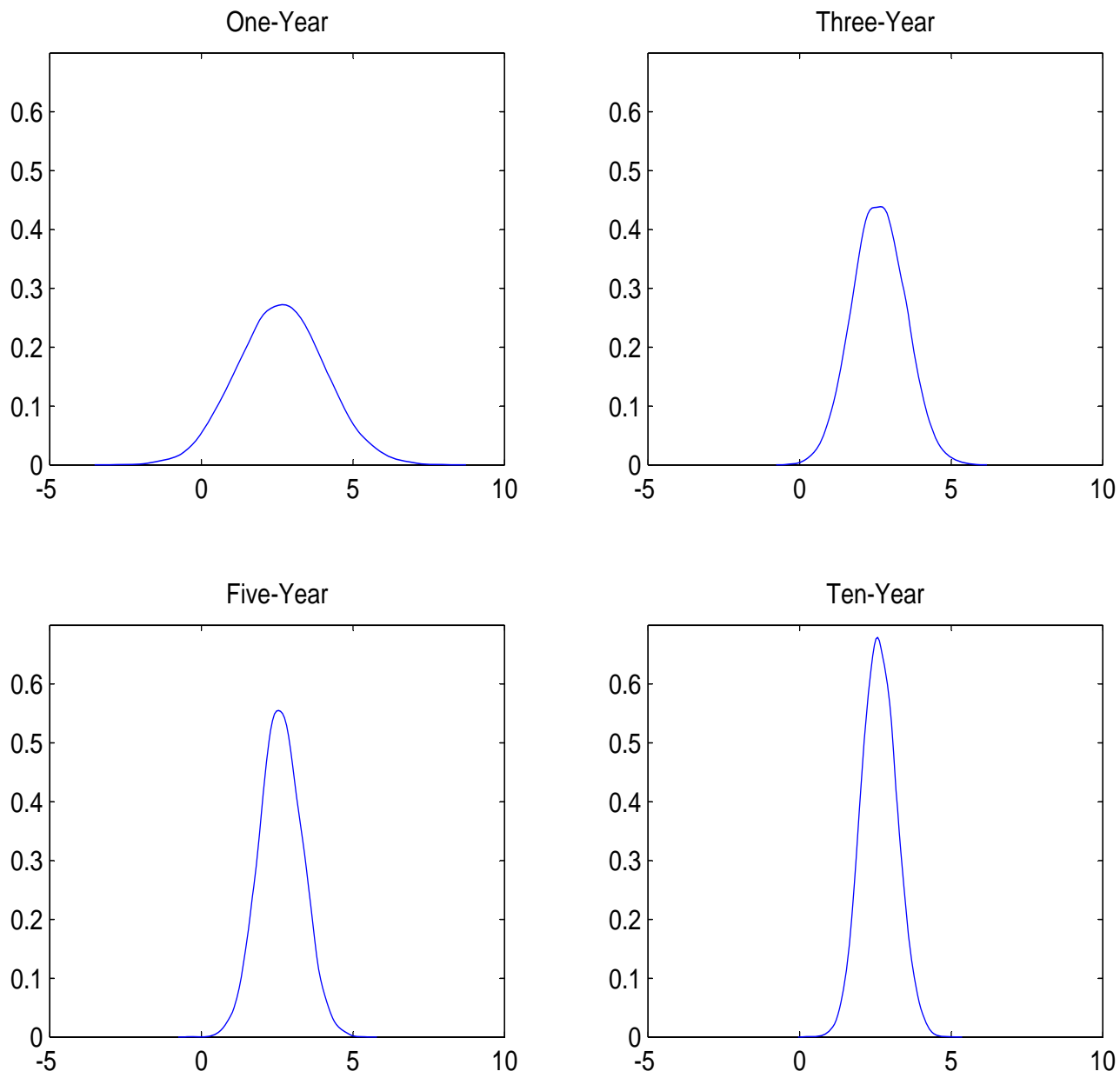

Notes: This shows the pdf for average CPI inflation over selected horizons based on an AR(4) model with EGARCH $(1,1)$ shocks. The model was fitted to CPI data available as of June 10, 2010, and starting in 1960. 
Figure 8: PDF for Inflation Based on TVP-VAR Model
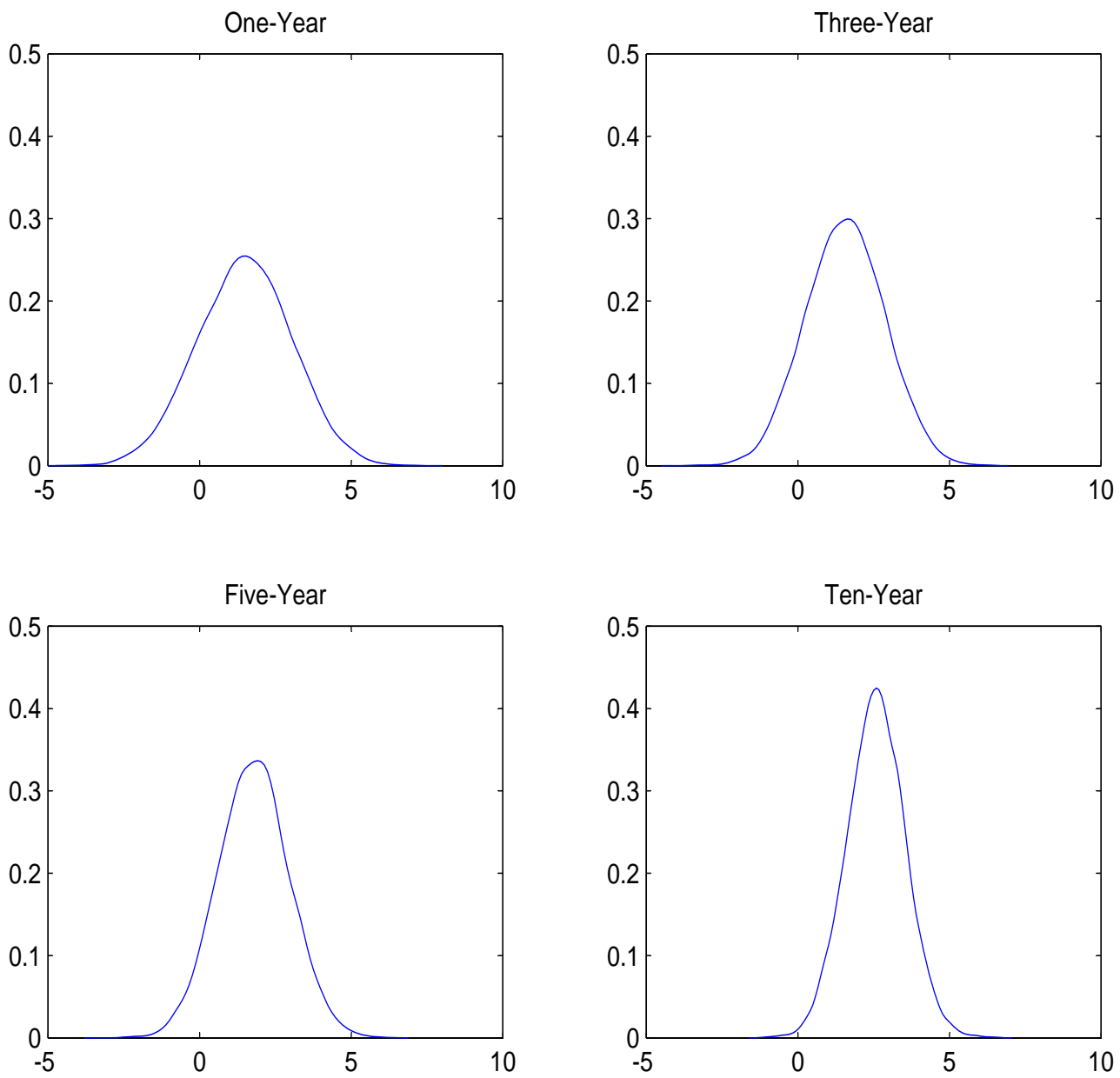

Notes: This shows the pdf for average CPI inflation over selected horizons based on a TVP-VAR model with stochastic volatility in CPI inflation, the federal funds rate and the unemployment rate. The model was fitted to data as observed as of June 10, 2010, and starting in 1960. 


\section{Figure 9: Empirical Pricing Kernel Using UCSV model}
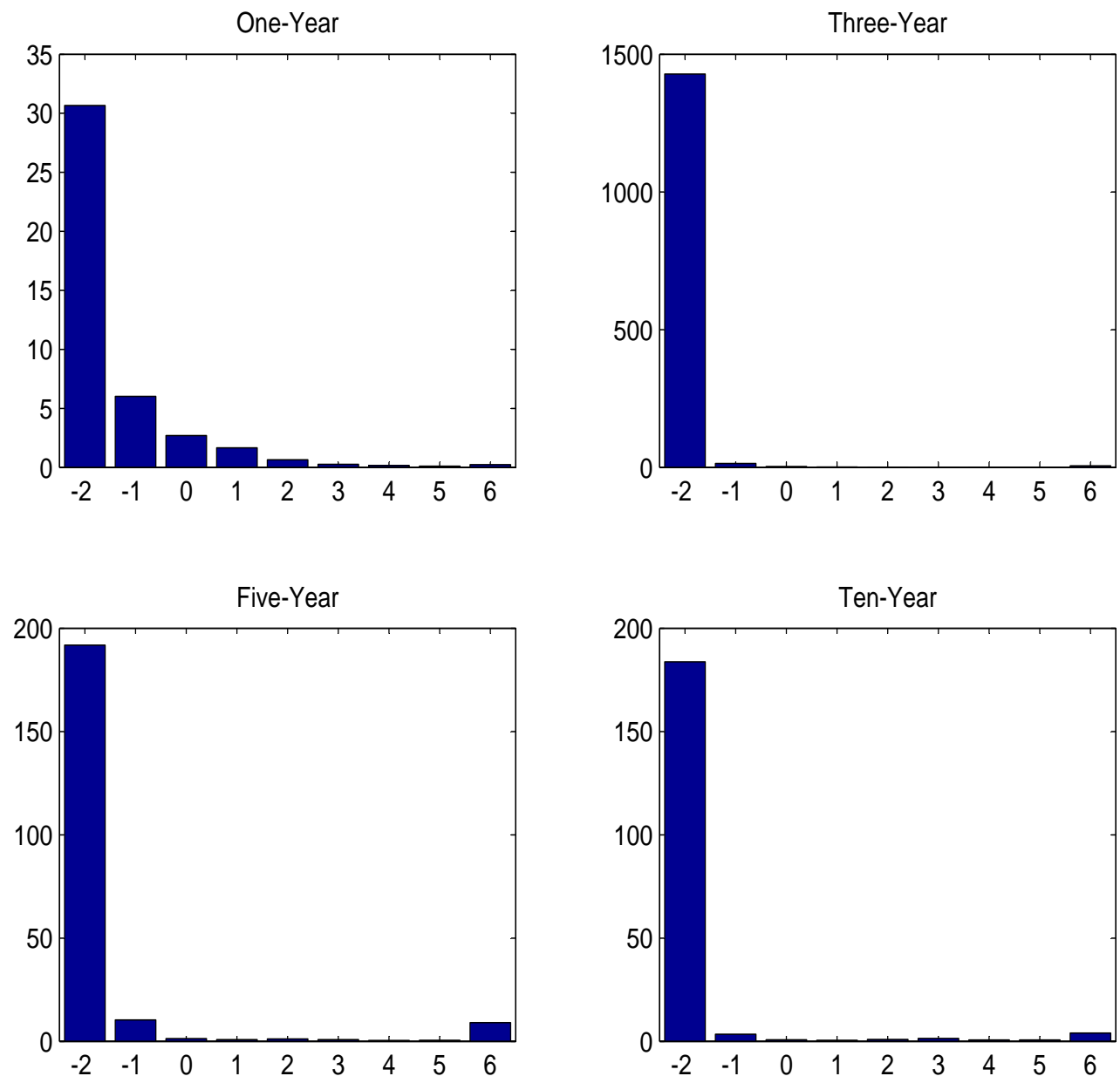

Notes: Ratio of Options-Implied PDF to Physical PDF based on UCSV model (Figures 1 and 5, respectively) on June 10, 2011 for inflation at selected maturities. 
Figure 10: Empirical Pricing Kernel Using UCSV model with Correlated Errors
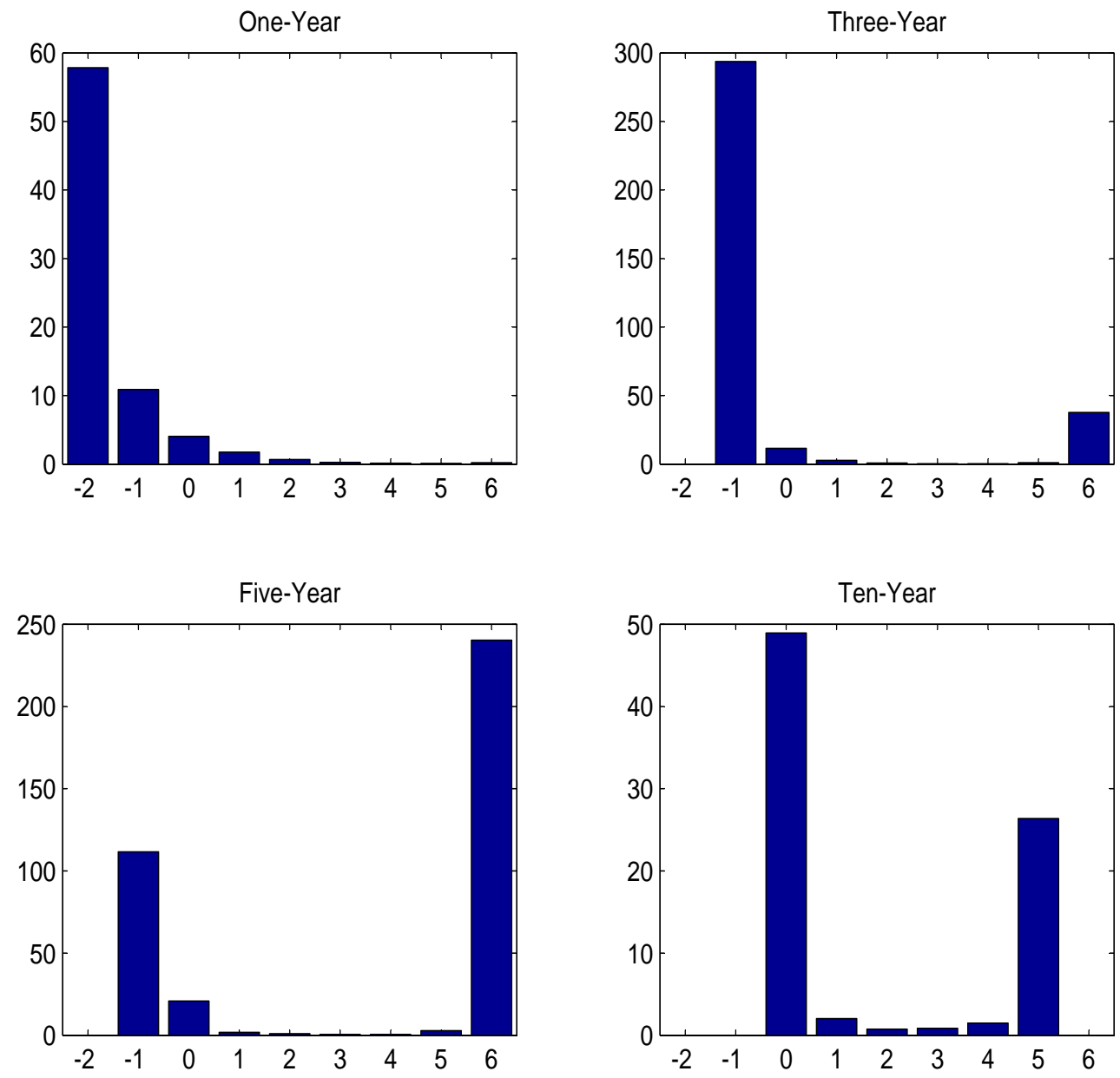

Notes: Ratio of Options-Implied PDF to Physical PDF based on UCSV model with correlated errors (Figures 1 and 6, respectively) on June 10, 2011 for inflation at selected maturities. 
Figure 11: Empirical Pricing Kernel Using AR-EGARCH model
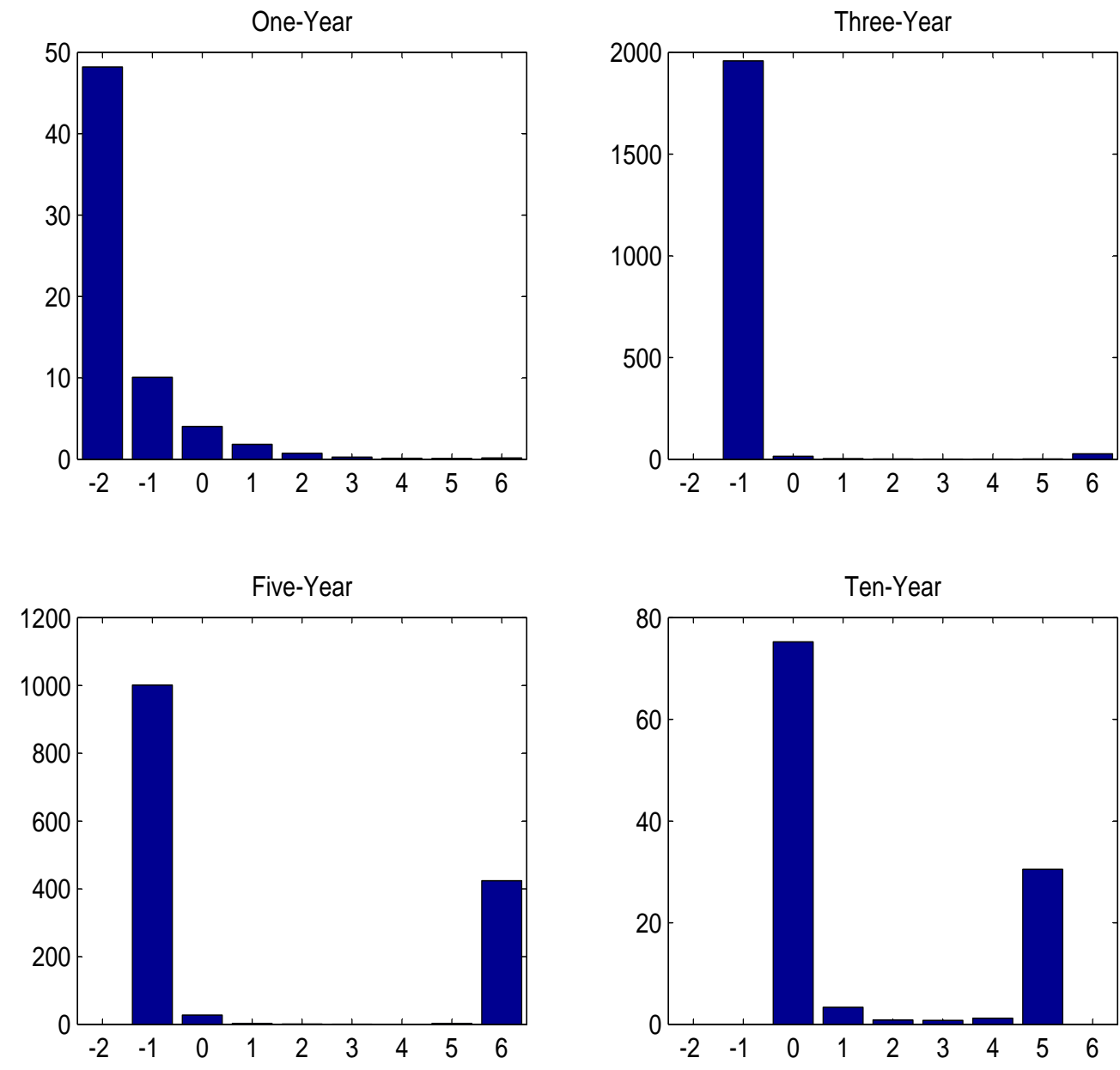

Notes: Ratio of Options-Implied PDF to Physical PDF based on AR-EGARCH model (Figures 1 and 7, respectively) on June 10, 2011 for inflation at selected maturities. 
Figure 12: Empirical Pricing Kernel Using TVP-VAR model
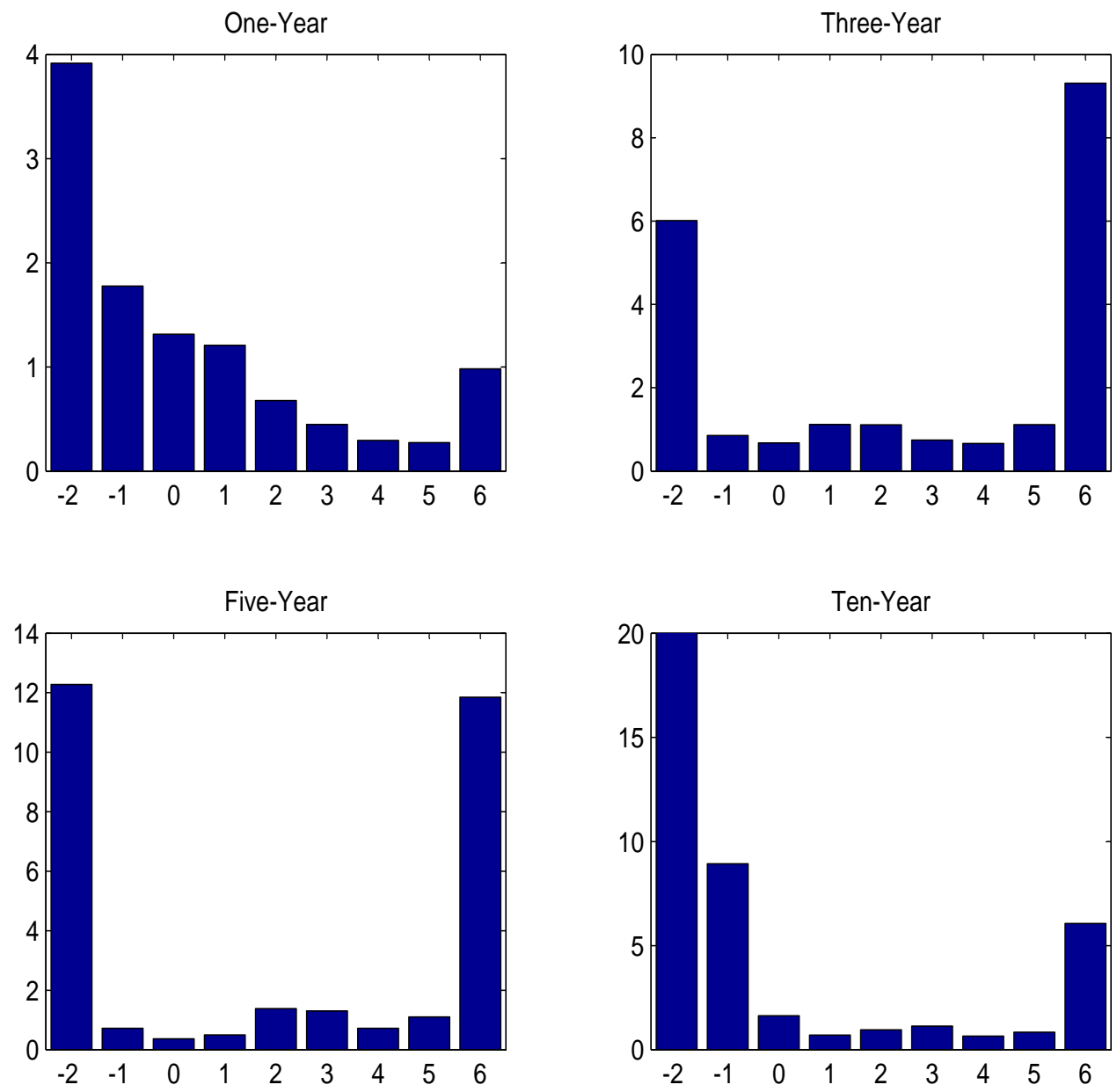

Notes: Ratio of Options-Implied PDF to Physical PDF based on TVP-VAR model (Figures 1 and 8, respectively) on June 10, 2011 for inflation at selected maturities. 


\section{Figure 13: Physical and Risk-Neutral Probabilities of Deflation}
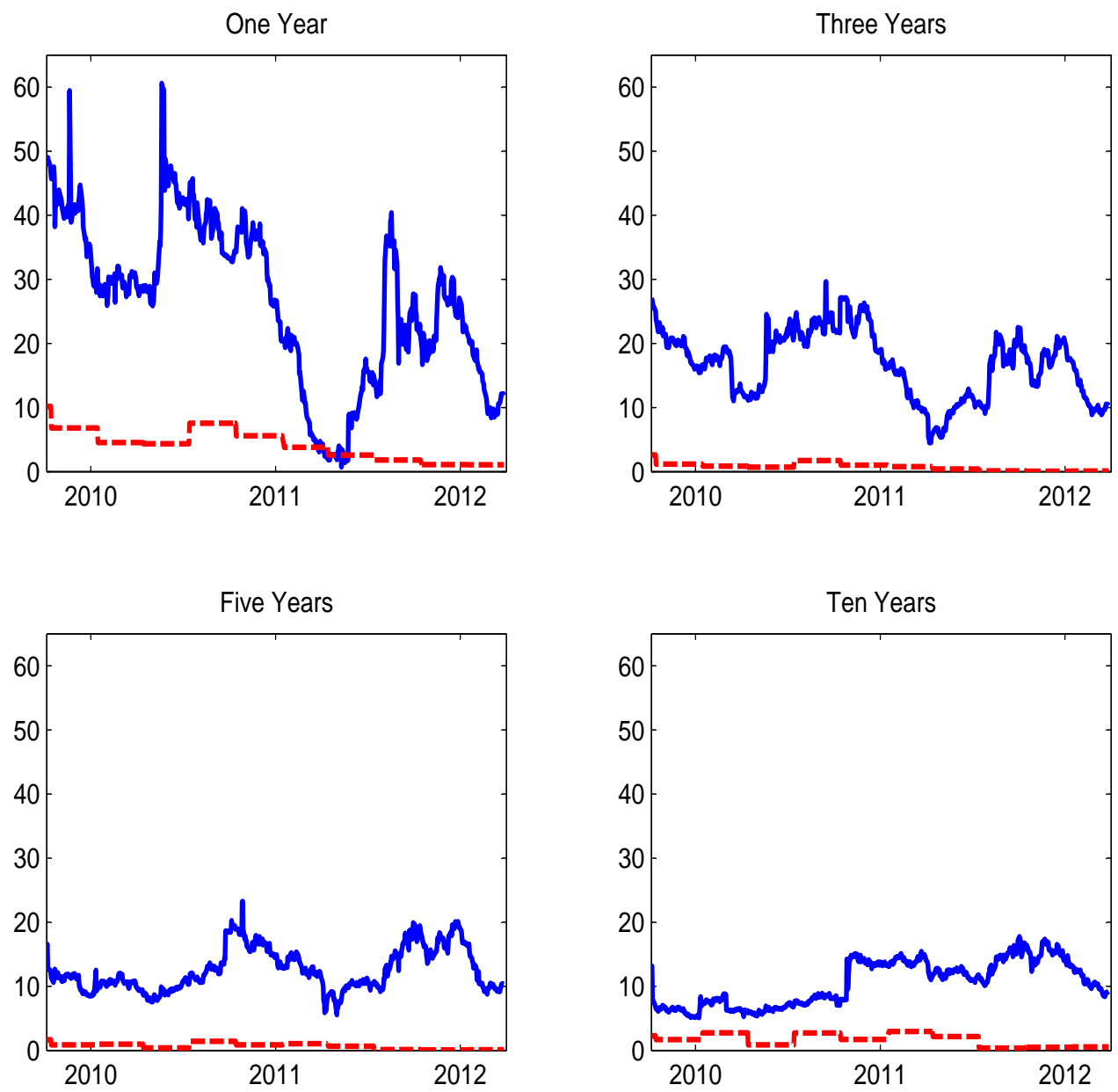

Notes: This shows the time series of probabilities of average CPI inflation over selected horizons being negative. These are constructed both (a) using inflation caps and floors, under an assumption of risk-neutrality (blue solid line) and (b) from the UCSV model (red dashed line). 
Figure 14: Risk-Neutral and Physical Probabilities of High Inflation
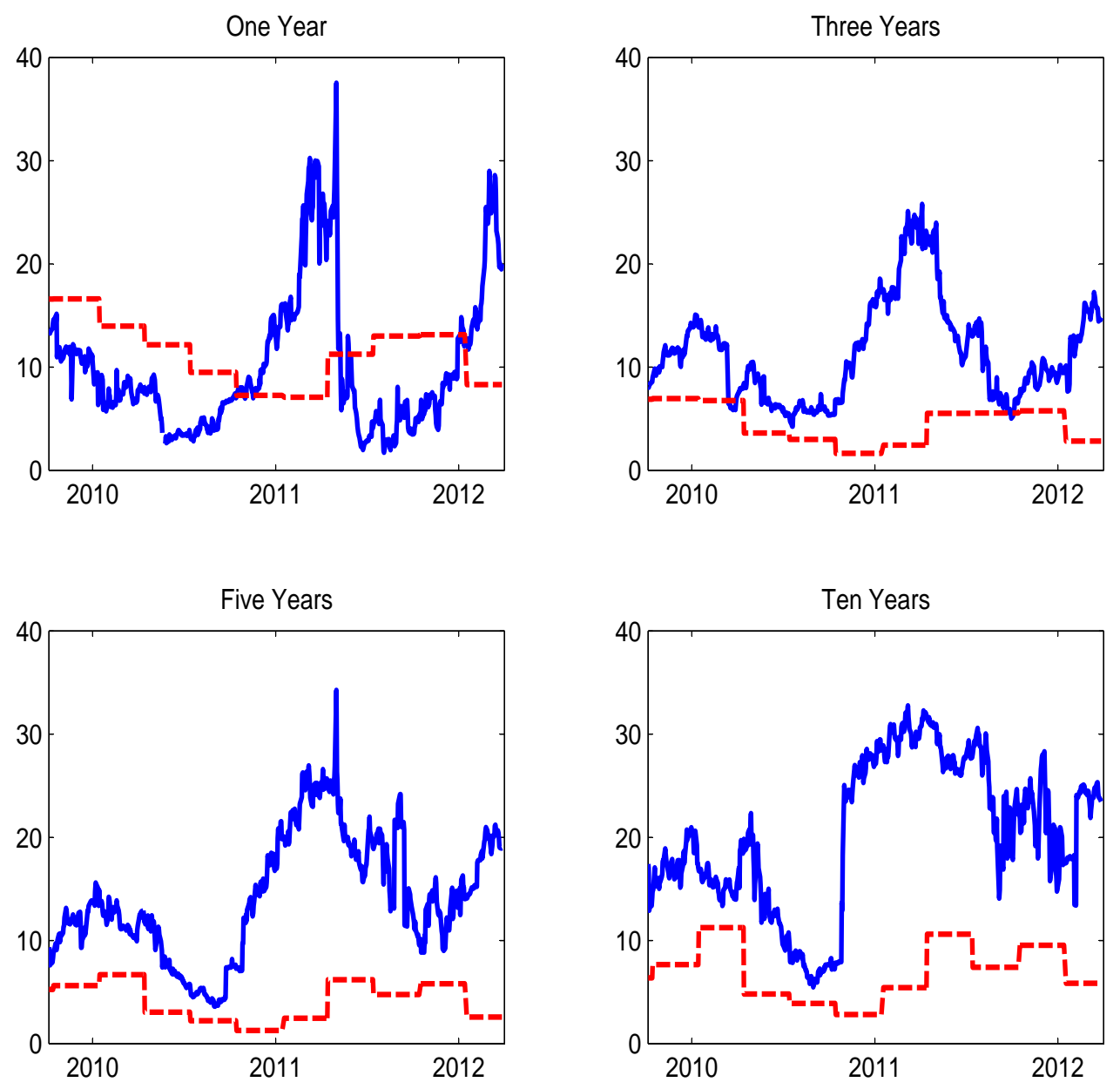

Notes: This shows the time series of probabilities of average CPI inflation over selected horizons exceeding 4 percent per annum. These are constructed both (a) using inflation caps and floors, under an assumption of risk-neutrality (blue solid line) and (b) from the UCSV model (red dashed line). 
Figure 15: Estimated Ten-Year Term Premium

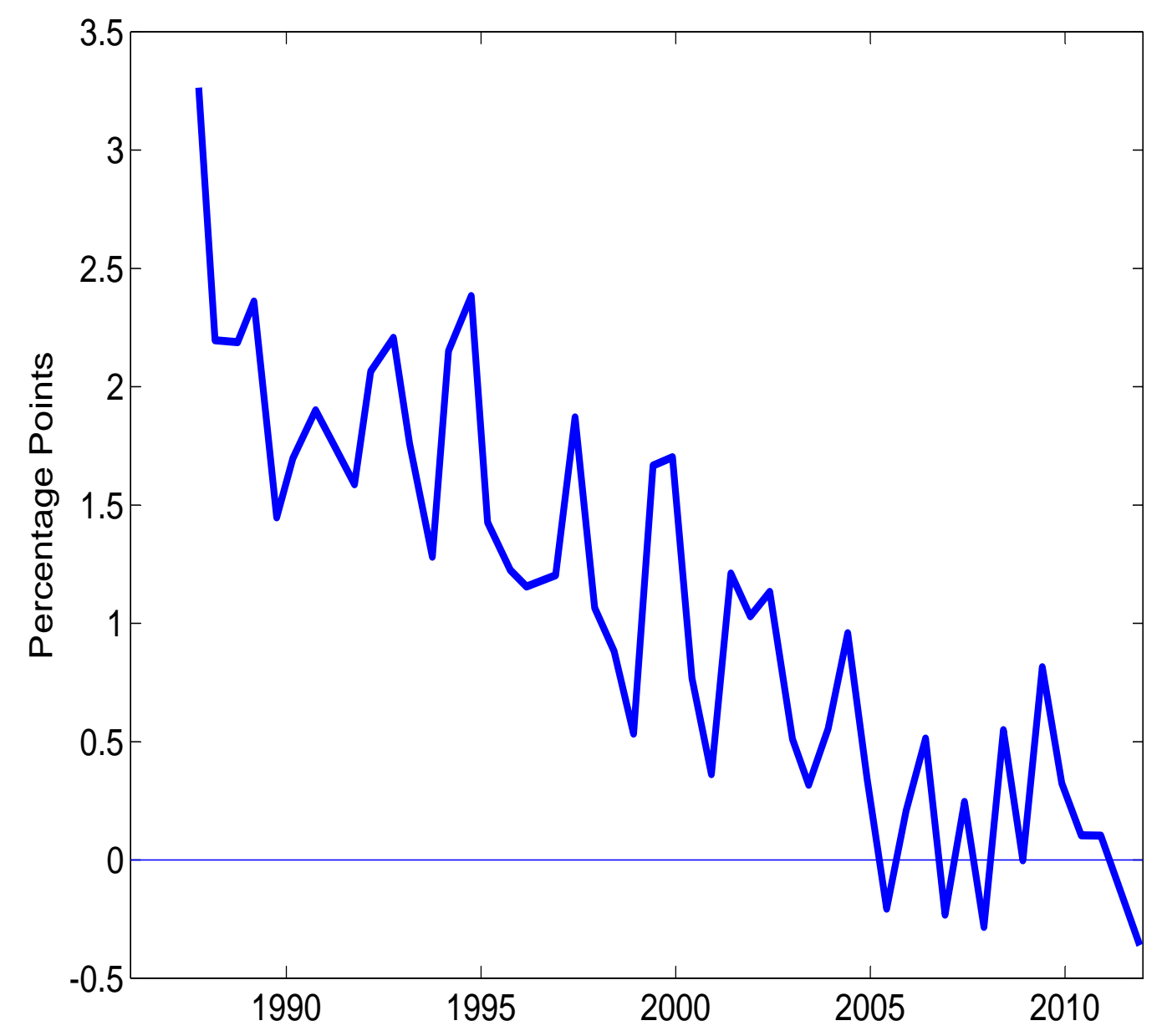

Notes: This shows the ten-year term premium, in percentage points. It is measured as the difference between the ten-year zero-coupon Treasury yield and the average expected three-month Treasury bill rate over the next ten years, taken from Blue Chip Financial Forecasts semiannual survey. 


\section{Figure 16: Five-to-Ten Year Forward Inflation PDFs}
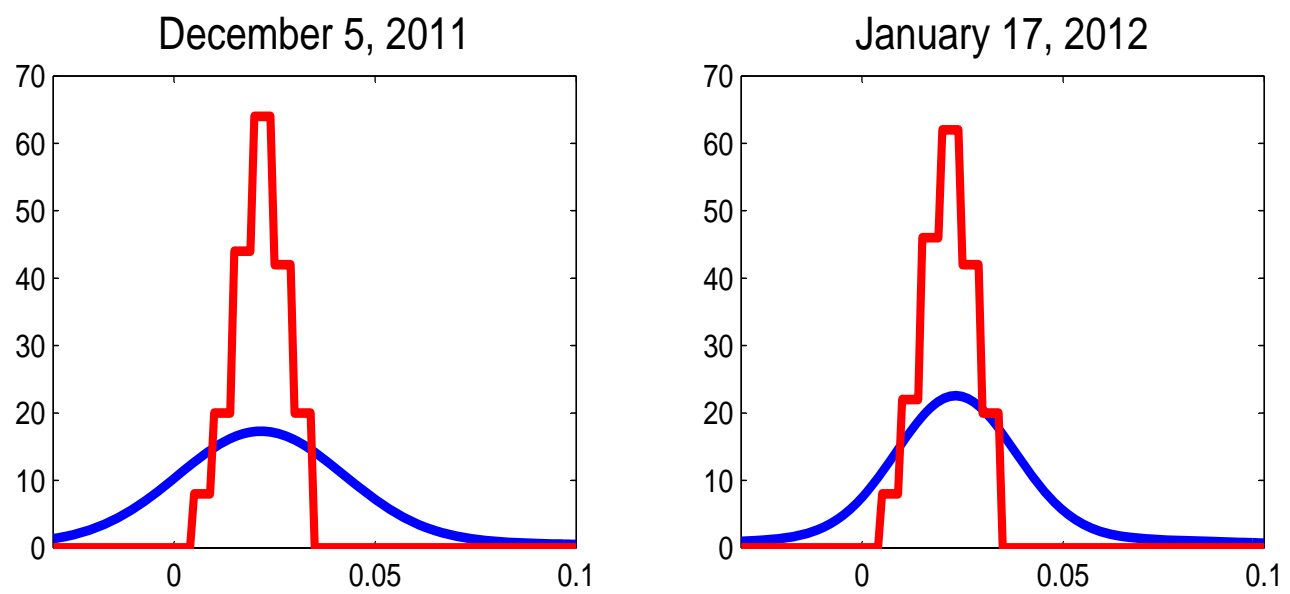

March 5, 2012
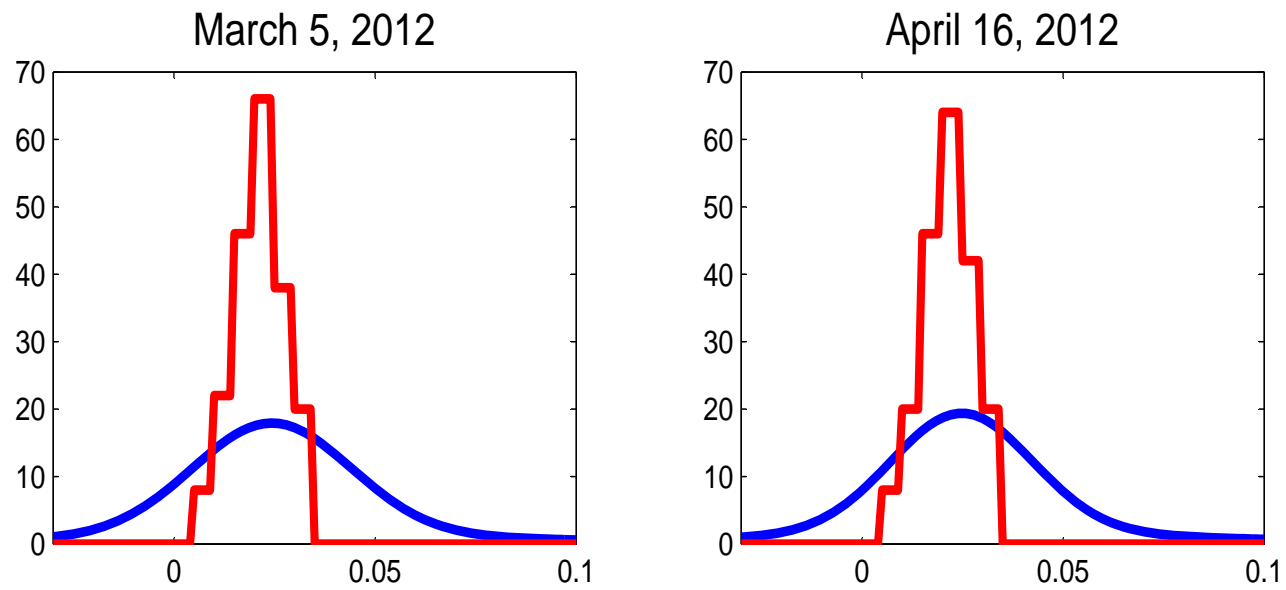

Notes: The blue curves show the pdfs for average CPI inflation from five to ten years hence derived from inflation floors and caps under an assumption of risk neutrality. The densities were obtained assuming that inflation over the first five and subsequent five years are independent mixed normal random variables. The red curves show the corresponding pdfs from the New York Feds survey of primary dealers. The pdfs are shown for all dates on which there is publicly available information for the New York Fed survey. 